\title{
Gene Expression Analysis of Peripheral Blood Leukocytes From Discordant Sib-Pairs With Schizophrenia and Bipolar Disorder Reveals Points of Convergence Between Genetic and Functional Genomic Approaches
} \author{
Marco Trauzzi, ${ }^{1,3}$ Heba Diab, ${ }^{1,3}$ Christopher P. Morley, ${ }^{1,2}$ Helena Medeiros, ${ }^{1,2}$ Antonio Macedo, ${ }^{6}$ \\ M. Helena Azevedo, ${ }^{6}$ and Michele T. Pato ${ }^{1,2,4,5}$ \\ ${ }^{1}$ Center for Neuropsychiatric Genetics, Upstate Medical University, Syracuse, New York \\ ${ }^{2}$ Department of Psychiatry, Upstate Medical University, Syracuse, New York \\ ${ }^{3}$ Department of Neuroscience and Physiology, Upstate Medical University, Syracuse, New York \\ ${ }^{4}$ Department of Psychiatry, Georgetown University, Washington, DC \\ ${ }^{5}$ Veterans Administration Medical Center, Washington, DC \\ ${ }^{6}$ Psicologia Medica, Universidade de Coimbra, Coimbra, Portugal
}

Frank A. Middleton,, ${ }^{1,2,3} *$ Carlos N. Pato, $, 2,4,5$ Karen L. Gentile, ${ }^{1,3}$ Lindsay McGann, ${ }^{1,3}$ Andrea M. Brown,,3

\begin{abstract}
We performed global RNA transcript analysis and comprehensive gene group analysis of peripheral blood leukocyte (PBL) RNA from two groups of matched sib-pairs that were discordant for either schizophrenia $(n=33$ sib-pairs) or bipolar disorder $(n=5$ sib-pairs). The pairs chosen for these analyses were selected from families with known patterns of genetic linkage (5q for schizophrenia and $6 q$ for bipolar disorder). At the single gene level, we obtained lists of the transcripts with the most significant changes in expression and from these lists determined those with the highest degree of predictive power for classifying subjects according to diagnosis in these samples. At the gene group level, we comprehensively analyzed pairwise expression changes of more than 4,000 functional groups and cytogenetic locations, and present a novel method of displaying these data that we term "cytogenomic" mapping. Verification of selected changes in expression was performed using quantitative real-time RT-PCR. Our results provide compelling evidence for the utility of analyzing PBL RNA for changes in expression in neuropsychiatric disorders. (C) 2005 Wiley-Liss, Inc.
\end{abstract}

KEY WORDS: microarray; GeneChip; white blood cell; RNA

The work was performed at Center for Neuropsychiatric Genetics, Upstate Medical University, Syracuse, NY 13210; Department of Psychiatry, Upstate Medical University, Syracuse, NY 13210; and Department of Neuroscience and Physiology, Upstate Medical University, Syracuse, NY 13210.

Grant sponsor: VA Merit Award; Grant sponsor: NIMH; Grant numbers: MH52618, MH058693.

*Correspondence to: Dr. Frank A. Middleton, Department of Neuroscience and Physiology, 3281 Weiskotten Hall, Upstate Medical University, 750 East Adams Street, Syracuse, NY 13210. E-mail: middletf@upstate.edu

Received 20 September 2004; Accepted 2 December 2004

DOI 10.1002/ajmg.b.30171

\section{INTRODUCTION}

We have recently reported strong suggestive genomewide linkages for both schizophrenia and bipolar disorder in pedigrees from the Portuguese Island Collection [PIC; see Pato et al., 2004; Sklar et al., 2004]. In a follow-up study of bipolar disorder using a denser SNP-based genotyping method, we achieved genome-wide significance for linkage at $6 q 22$ [Middleton et al., 2004]. In schizophrenia, the peak linkage signals were obtained on chromosome 5q31-35. In order to help expedite the selection of candidate genes in these (and other) regions, we have implemented a strategy involving the measurement of changes in gene expression in peripheral blood leukocytes (PBLs) in discordant sib-pairs from the two pedigree sets.

The analysis of mRNA transcript levels in PBLs from living subjects offers several advantages compared with studies involving only end point postmortem tissue specimens. Such advantages include the ability to completely match subject characteristics such as age, gender, family background, time of blood draw, geographical/environmental variables, diet, and the cellular composition of the samples. Moreover, it also becomes feasible to design studies that examine expression profiles of PBLs during the progression of the disease, or in response to drug treatments. These gene expression patterns, when obtained in well-controlled studies, have increased the power to help refine candidate gene selection for mutational screening, as well as obtain lists of genes with predictive power for classifying different diseases and their treatment response. Indeed, in the cancer field, it has become standard practice at some clinics that specialize in childhood leukemias to compare the expression profiles of PBLs or lymphocytes on all patients. These expression patterns not only correctly subtype the leukemia, but also serve as highly accurate predictors of the disease course [e.g., Yeoh et al., 2002].

In neuropsychiatric diseases, no studies to date have been published on the potential utility of gene expression profiling of PBLs for either diagnosis or disease characterization. There has been, however, at least one study to date examining the gene expression profile of transformed lymphoblasts from a small number of subjects with schizophrenia in a single pedigree, which showed promising results [Vawter et al., 2004]. In the present, study, we wished to determine the changes in gene expression in a larger sample involving 33 sib-pairs from families segregating for schizophrenia from the PIC population where we had detected strong linkage to 5q. 
TABLE I. Largest Significant Pairwise Expression Changes in Schizophrenia Sib Pairs

\begin{tabular}{|c|c|c|c|c|c|}
\hline Probe ID & Fold change & $P$-value & Gene title & Symbol & Location \\
\hline \multicolumn{6}{|c|}{ Increased expression } \\
\hline 201743_at & 2.53 & 0.00108 & CD14 antigen & CD14 & $5 q 31.1$ \\
\hline $202437^{-} \mathrm{s}$ at & 2.36 & 0.00864 & Cytochrome P 450 , family 1 , subfamily B, polypeptide 1 & CYP1B1 & $2 \mathrm{p} 21$ \\
\hline 204614_at & 2.33 & 0.00331 & $\begin{array}{l}\text { Serine (or cysteine) proteinese inhibitor, clade B } \\
\text { (ovalbumin), member } 2\end{array}$ & SERPINB2 & $18 \mathrm{q} 21.3$ \\
\hline 201109_s_at & 2.16 & 0.00990 & Thrombospondin 1 & THBS1 & $15 q 15$ \\
\hline 221731 x at & 2.08 & 0.01777 & Chondroitin sulfate proteoglycan 2 (versican) & CSPG2 & $5 q 14.3$ \\
\hline 212681 at & 2.04 & 0.02058 & Erythrocyte membrane protein band 4.1-like 3 & EPB41L3 & $18 \mathrm{p} 11.32$ \\
\hline 210111_s_at & 2.02 & 0.00043 & KIAA0265 protein & KIAA0265 & $7 q 32.3$ \\
\hline 205098 at & 1.97 & 0.00330 & Chemokine (C-C motif) receptor 1 & CCR1 & $3 \mathrm{p} 21$ \\
\hline 217996 at & 1.96 & 0.00407 & Pleckstrin homology-like domain, family A, member 1 & PHLDA1 & $12 \mathrm{q} 15$ \\
\hline 202435 s at & 1.96 & 0.03702 & Cytochrome P450, family 1 , subfamily B, polypeptide 1 & CYP1B1 & $2 \mathrm{p} 21$ \\
\hline $201110 \mathrm{~s}$ at & 1.90 & 0.04771 & Thrombospondin 1 & THBS1 & $15 \mathrm{q} 15$ \\
\hline $20436 \overline{\mathrm{s}}$ at & 1.90 & 0.04004 & Cytochrome P450, family 1 , subfamily B, polypeptide 1 & CYP1B1 & $2 \mathrm{p} 21$ \\
\hline 218559 _s_at & 1.86 & 0.00091 & $\begin{array}{l}\text { v-maf musculoaponeurotic fibrosarcoma oncogene homolog } \\
\text { B (avian) }\end{array}$ & MAFB & $20 \mathrm{q} 11.2-\mathrm{q} 13.1$ \\
\hline 217997_at & 1.85 & 0.01743 & Pleckstrin homology-like domain, family A, member 1 & PHLDA1 & $12 q 15$ \\
\hline 212636 at & 1.82 & 0.00120 & Quaking homolog, KH domain RNA binding (mouse) & QKI & $6 \mathrm{q} 26-27$ \\
\hline 211776_s_at & 1.80 & 0.01556 & Erythrocyte membrane protein band 4.1-like 3 & EPB41L.3 & $18 \mathrm{p} 11.32$ \\
\hline $206710 \mathrm{~s}$ at & 1.80 & 0.01838 & Erythrocyte membrane protein band 4.1-like 3 & EPB41L.3 & $18 \mathrm{p} 11.32$ \\
\hline 204470 at & 1.77 & 0.02088 & Chemokine (C-X-C motif) ligand 2 & CXCL2 & $4 \mathrm{q} 21$ \\
\hline 212993 at & 1.77 & 0.01313 & Sin 3 -associated polypetide, $18 \mathrm{kDa}$ & - & $9 q 34.3$ \\
\hline $218195^{-}$at & 1.76 & 0.00527 & Chromosome 6 open reading frame 211 & C6orf211 & $6 \mathrm{q} 25.1$ \\
\hline 208892_a_at & 1.75 & 0.01232 & Dual specificity phosphatase 6 & DUSP6 & $12 q 22-q 23$ \\
\hline 204620_s_at & 1.75 & 0.03852 & Chondroitin sulfate proteoglycan 2 & CSPG2 & $5 q 14.3$ \\
\hline $201694 \mathrm{~s}$ at & 1.74 & 0.01116 & Early growth response 1 & EGR1 & $5 q 31.1$ \\
\hline 213836 s-at & 1.74 & 0.00421 & Hypothetical protein FLJ10055 & FLJ10055 & $17 q 24.3$ \\
\hline $206343 \mathrm{~s}$ at & 1.73 & 0.01010 & Neuregulin 1 & NRG1 & 8p21-p12 \\
\hline 204049_s_at & 1.72 & 0.02217 & Phosphatase and actin regulator 2 & PHACTR2 & $6 q 24.1$ \\
\hline 204619 s at & 1.69 & 0.03953 & Chondroitin sulfate proteoglycan 2 (versican) & CSPG2 & $5 q 14.3$ \\
\hline 201108 s at & 1.69 & 0.02084 & Thrombospondin 1 & THBS1 & $15 \mathrm{q} 15$ \\
\hline 203973 s-at & 1.67 & 0.00375 & CCAAT/enhancer binding protein $(\mathrm{C} / \mathrm{EBP})$, delta & CEBPD & $8 \mathrm{p} 11.2-\mathrm{p} 11.1$ \\
\hline 205863 at & 1.67 & 0.03650 & S100 calcium binding protein A12 (calgranulin C) & S100A12 & $1 \mathrm{q} 21$ \\
\hline 207719_x_at & 1.66 & 0.02342 & KARP-1 binding protein & $\mathrm{KAB}$ & $1 q 44$ \\
\hline $222243 \mathrm{~s}$ at & 1.65 & 0.00014 & Transducer of ERBB2, 2 & TOB2 & $22 \mathrm{q} 13.2-\mathrm{q} 13.31$ \\
\hline 205922 at & 1.65 & 0.00371 & Vanin 2 & VNN2 & $6 \mathrm{q} 23-\mathrm{q} 24$ \\
\hline 222028_at & 1.65 & 0.00093 & $\begin{array}{l}\text { Zinc finger protein } 45 \text { (a Kruppel-associated box (KRAB) } \\
\text { domain polypeptide) }\end{array}$ & ZNF45 & $19 \mathrm{q} 13.2$ \\
\hline 220088_at & 1.64 & 0.03512 & Complement component 5 receptor 1 (C5a ligand) & C5R1 & 19p13.3-q13.4 \\
\hline 205495 s at & 1.63 & 0.01893 & Granulysin & GNLY & $2 \mathrm{p} 12-\mathrm{q} 11$ \\
\hline $210844 \times$ at & 1.63 & 0.00142 & Catenin (cadherin-associated protein), alpha 1, $102 \mathrm{kDa}$ & CTNNA1 & $5 q 31$ \\
\hline $208891^{-a t}$ & 1.63 & 0.01859 & Dual specificity phosphatase 6 & DUSP6 & $12 q 22-q 23$ \\
\hline $208716 \mathrm{~s}$ at & 1.63 & 0.00689 & Putative membrane protein & LOC54499 & $1 \mathrm{q} 22-\mathrm{q} 25$ \\
\hline 200765_x_at & 1.62 & 0.00056 & Catenin (cadherin-associated protein), alpha 1, $102 \mathrm{kDa}$ & CTNNA1 & $5 q 31$ \\
\hline \multicolumn{6}{|c|}{ Decrease $\bar{d}$ expression } \\
\hline 209170 s at & -1.89 & 0.01378 & Glycoprotein M6B & GPM6B & $\mathrm{Xp} 22.2$ \\
\hline 213797 at & -1.65 & 0.02433 & Viperin & cig5 & $2 \mathrm{p} 25.2$ \\
\hline $212621^{-}$at & -1.63 & 0.01017 & KIAA0286 protein & KIAA0286 & $12 \mathrm{q} 13.2$ \\
\hline 214059 at & -1.61 & 0.03891 & Interferon-induced protein 44 & IFI44 & $1 \mathrm{p} 31.1$ \\
\hline 219863 at & -1.61 & 0.01801 & Cyclin-E binding protein 1 & CEB1 & $4 q 22.1-q 23$ \\
\hline $210797^{-}$s at & -1.60 & 0.00820 & $2^{\prime}-5^{\prime}$-oligoadenylate synthetase-like & OASL & $12 \mathrm{q} 24.2$ \\
\hline 214453 s at & -1.55 & 0.04213 & Interferon-induced protein 44 & IFI44 & $1 \mathrm{p} 31.1$ \\
\hline $216252 \times$ at & -1.50 & 0.02649 & Tumor necrosis factor receptor superfamily, $\mathrm{m}$ & TNFRSF 6 & $10 \mathrm{q} 24.1$ \\
\hline 205660 at & -1.47 & 0.00608 & $2^{\prime}-5^{\prime}$-oligoadenylate synthetase-like & OASL & $12 \mathrm{q} 24.2$ \\
\hline $210676^{-} \mathrm{x}$ at & -1.45 & 0.01189 & RAN binding protein 2 -like 1 & RANBP2L1 & $2 q 13$ \\
\hline $204780 \mathrm{~s}$ at & -1.44 & 0.00725 & Tumor necrosis factor receptor superfamily, member 6 & TNFRSF6 & $10 \mathrm{q} 24.1$ \\
\hline $210425 \times$ at & -1.44 & 0.03848 & Golgin-67 & GOLGIN-67 & $15 q 11.2$ \\
\hline $204747^{-a t}$ & -1.42 & 0.02484 & Interferon-induced protein with tetratricopeptide repeats 4 & IFIT4 & $10 \mathrm{q} 24$ \\
\hline 215831_at & -1.42 & 0.02860 & PRO1621 protein & PRO1621 & 11 \\
\hline 203992_s_at & -1.41 & 0.00763 & $\begin{array}{l}\text { Ubiquitously transcribed tetratricopeptide repeat, } \\
\mathrm{X} \text { chromosome }\end{array}$ & UTX & $\mathrm{Xp} 11.2$ \\
\hline 220104 at & -1.41 & 0.01244 & Zinc finger $\mathrm{CCCH}$ type, antiviral 1 & ZC3HAV1 & $7 q 34$ \\
\hline 213703 at & -1.36 & 0.00483 & Hypothetical protein LOC150759 & LOC150759 & $2 \mathrm{q} 11.2$ \\
\hline $204083 \mathrm{~s}$ at & -1.35 & 0.02416 & Tropomyosin 2 (beta) & TPM2 & $9 \mathrm{p} 13.2-\mathrm{p} 13.1$ \\
\hline 204369 at & -1.34 & 0.04573 & Phosphoinositide-3-kinase, catalytic, alpha polypeptide & PIK3CA & $3 q 26.3$ \\
\hline 216358_at & -1.33 & 0.01088 & $\begin{array}{l}\text { SWI/SNF related, matrix associated actin dependent } \\
\text { regulator of chromatin, subfamily e } 1\end{array}$ & SMARCE1 & $17 \mathrm{q} 21.2$ \\
\hline 217506_at & -1.30 & 0.00600 & $\begin{array}{l}\text { Transcribed sequence with moderate similarity to } \\
\text { hypothetical protein FLJ20378 }\end{array}$ & - & - \\
\hline
\end{tabular}


TABLE I. (Continued)

\begin{tabular}{|c|c|c|c|c|c|}
\hline Probe ID & Fold change & $P$-value & Gene title & Symbol & Location \\
\hline $208931 \mathrm{~s}$ at & -1.30 & 0.00297 & Interleukin enhancer binding factor $3,90 \mathrm{kDa}$ & ILF3 & $19 \mathrm{p} 13.2$ \\
\hline $214982^{-}$at & -1.30 & 0.00598 & U5 snRNP-specific protein, $200-\mathrm{KD}$ & U5-200KD & $2 q 11.2$ \\
\hline 210232_at & -1.30 & 0.02568 & Cell division cycle 42 (GTP binding protein, $25 \mathrm{kDa}$ ) & CDC42 & 1p36.1 \\
\hline $216110^{-} \mathrm{x}$ at & -1.30 & 0.04868 & Homo sapiens cDNA FLJ14080 fis, clone HEMBB1002152 & - & $2 q 31.1$ \\
\hline 222307_ā̄ & -1.30 & 0.02200 & Hypothetical protein LOC282997 & LOC282997 & $10 \mathrm{q} 25.3$ \\
\hline 219209_at & -1.30 & 0.01517 & Melanoma differentiation associated protein -5 & MDA5 & $2 \mathrm{p} 24.3-\mathrm{q} 24.3$ \\
\hline $207115^{-} \mathrm{x}$ at & -1.29 & 0.02557 & mbt domain containing 1 & MBTD1 & $17 q 21.33$ \\
\hline 220809_ā̄ & -1.28 & 0.03526 & Hypothetical protein FLJ14327 & FLJ14327 & $16 \mathrm{q} 23.2$ \\
\hline $210095 \mathrm{~s}$ at & -1.28 & 0.00346 & Insulin-like growth factor binding protein 3 & IGFBP3 & $7 q 13 q-12$ \\
\hline 221728_x_at & -1.28 & 0.01621 & $\mathrm{X}$ (inactive)-specific transcript & XIST & Xq13.2 \\
\hline 217104_at & -1.28 & 0.02709 & Hypothetical protein LOC283687 & LOC283687 & $15 \mathrm{q} 24.3$ \\
\hline $211115^{-} \mathrm{x}$ at & -1.28 & 0.00056 & Survival of motor neuron protein interacting protein 1 & SIP1 & $14 \mathrm{q} 13$ \\
\hline 209321_s_at & -1.28 & 0.00881 & Adenylate cyclase 3 & ADCY3 & 2p24-p22 \\
\hline $209387^{-}$s at & -1.28 & 0.03185 & Transmembrane 4 superfamily member 1 & TM4SF1 & $3 q 21-q 25$ \\
\hline 209314 s at & -1.28 & 0.00716 & HBS1-like (S. cerevisiae) & HBS1L & $6 q 23-q 24$ \\
\hline 214487_s_at & -1.27 & 0.01701 & RAP2B, member of RAS oncogene family & RAP2B & $3 \mathrm{q} 25.2$ \\
\hline $202861^{-}$at & -1.27 & 0.03941 & Period homolog 1 (Drosophila) & PER1 & 17p13.1-p12 \\
\hline 218706_s_at & -1.27 & 0.01122 & HCV NS3-transactivated protein 2 & NS3TP2 & $5 \mathrm{q} 23.3$ \\
\hline 220704_at & -1.27 & 0.01071 & Zinc finger protein, subfamily 1A, 1 (Ikaros) & ZNFN1A1 & $7 \mathrm{p} 13-\mathrm{p} 11.1$ \\
\hline
\end{tabular}

Shading indicates more than one probe set identified a change in this transcript among those listed in this table; these can be considered independent validations.

In addition, we performed a highly focused analysis of gene expression alterations in five sib-pairs from specific PIC families segregating for bipolar disorder that had linkage to $6 \mathrm{q} 22$. Our aims were to determine if this approach would have diagnostic utility and also help identify candidate genes with abnormal expression patterns in the regions that display significant linkage. Importantly, we have not assumed a priori that the changes in transcript levels that occur in PBLs necessarily indicate that similar patterns of expression alterations will be evident in the brains of subjects with schizophrenia or bipolar disorder. Rather, we merely hypothesized that if underlying genetic abnormalities altered transcript expression in a consistent manner, we would be able to detect such effects if the transcript was expressed in PBLs. We suggest that such changes, when present, may reflect primary pathogenetic mechanisms, or simply conserved pathophysiological features of the illness or its treatment.

\section{METHODS}

\section{Subject Ascertainment}

Methods for subject ascertainment and classification are the same as previously described [Pato et al., 2004]. Families with two or more affected individuals were ascertained from systematic screening of all treating clinicians, treatment facilities, social services, and extensive family interviews. In the Azores, all four psychiatric hospitals and the two general hospitals participated in the study. Similarly in Madeira, both psychiatric hospitals and the general hospital participated. On the mainland, families were identified by our collaborators at the University of Coimbra. Informed consent was obtained in writing from all subjects for participation in the genetic and family studies. Collection of blood and family history information was approved by all of the appropriate Institutional Review Boards. Best estimate diagnoses according to DSM-IV were made by two independent blinded researchers. All cases, where there was disagreement, were reviewed by a third senior psychiatrist blind to the status of the case (MT Pato, MD).

The specific subjects for this study were selected as genderand age-matched discordant sibs from families that participated in our linkage studies. For studies of schizophrenia, 40 such sib-pairs were selected from all families segregating for schizophrenia from the PIC population where we had detected strong linkage to $5 q$ and had cell samples available for RNA purification. For bipolar disorder, we performed a highly focused analysis of gene expression alterations in five sib-pairs from specific PIC families segregating for bipolar disorder with linkage to $6 \mathrm{q} 22$. These 45 age- and gender-matched sib-pairs were screened for alterations in white blood cell composition (see below), which eliminated five schizophrenia sib-pairs from further consideration. After processing all arrays, a priori quality control criteria (excessive $3^{\prime} / 5^{\prime}$ ratios for beta actin and GAPDH, and/or scale factors exceeding 10.0 for any subject) led us to eliminate two additional sib-pairs from our analyses. Thus, in total, 33 sib-pairs were used for our schizophrenia studies and five sib-pairs for our bipolar studies. To achieve the highest level of subject matching and quality control, we found it helpful to examine cellular composition using differential white blood cell counts (Wright's stain method). All of the samples included in this report had normal blood count differentials. The specific age and blood cell composition values for the schizophrenic group are the same as previously described (Petryshen et al., 2004; 22 female pairs, 11 male pairs; mean ages \pm SD of affecteds and unaffecteds $=44.8 \pm 12.4$ and $42.8 \pm 12.9$, respectively; mean neutrophil counts $=$ $58.9 \pm 4.8 \%$ and $56.8 \pm 4.7 \%$; mean lymphocyte counts $=$ $34.1 \pm 7.0 \%$ and $33.9 \pm 4.2 \%$ ). For the bipolar subject pairs, the mean values \pm SD for affecteds and unaffecteds was age $=41.2 \pm 5.8$ and $40.8 \pm 11.4 ; \quad$ neutrophils $=55.4 \pm 4.4$ $59.2 \pm 2.9 ;$ lymphocytes $=38.4 \pm 4.7,35.2 \pm 2.8$. There were no significant pairwise or unpaired differences between the subject groups and the matched controls for any of these values.

\section{Microarray Gene Expression Sample Preparation}

Total RNA was extracted from leukocyte cell preparations from 66 siblings selected from the 40 schizophrenia pedigrees used in a previous linkage study [see Sklar et al., 2004] and 10 siblings selected from the 25 bipolar pedigrees used in a previous linkage study [see Middleton et al., 2004]. Total RNA quality and quantity was assessed using UV spectrophotometry and comparison of $28 \mathrm{~S}: 18 \mathrm{~S}$ ratios with the Bioanalyzer RNA Nano Chip (Agilent). Microarray samples were labeled and processed according to standard protocols, 
TABLE II. Largest Significant Pairwise Expression Changes in Bipolar Sibling Pairs

\begin{tabular}{|c|c|c|c|c|c|}
\hline Probe ID & Fold change & $P$-value & Gene title & Symbol & Location \\
\hline \multicolumn{6}{|c|}{ Increased expression } \\
\hline 203556 at & 2.08 & 0.03908 & Zinc fingers and homeoboxes 2 & ZHX2 & $8 \mathrm{q} 24.13$ \\
\hline 209332_s_at & 1.94 & 0.01483 & MAX protein & MAX & $14 \mathrm{q} 23$ \\
\hline 202351_āt & 1.88 & 0.01839 & $\begin{array}{l}\text { Integrin, alpha } \mathrm{V} \text { (vitronectin receptor, alpha } \\
\text { polypeptide, antigen CD51) }\end{array}$ & ITGAV & 2q31-q32 \\
\hline 201648_at & 1.87 & 0.01542 & Janus kinase 1 (a protein tyrosine kinase) & JAK1 & 1p32.3-p31.3 \\
\hline $211994^{-}$at & 1.78 & 0.02617 & Protein kinase, lysine deficient 1 & PRKWNK1 & $12 \mathrm{p} 13.3$ \\
\hline 208638_at & 1.76 & 0.00846 & $\begin{array}{l}\text { Thioredoxin domain containing } 7 \\
\text { (protein disulfide isomerase) }\end{array}$ & TXNDC7 & $2 \mathrm{p} 25.1$ \\
\hline 208856_x_at & 1.76 & 0.03823 & Ribosomal protein, large, $\mathrm{PO}$ & RPLP0 & $12 \mathrm{q} 24.2$ \\
\hline 214737_x_at & 1.74 & 0.02115 & Heterogeneous nuclear ribonucleoprotein $\mathrm{C}(\mathrm{C} 1 / \mathrm{C} 2)$ & HNRPC & $14 \mathrm{q} 11.2$ \\
\hline 212626_x_at & 1.67 & 0.03681 & Heterogeneous nuclear ribonucleoprotein $\mathrm{C}(\mathrm{C} 1 / \mathrm{C} 2)$ & HNRPC & $14 \mathrm{q} 11.2$ \\
\hline 221491_x_at & 1.64 & 0.01463 & Major histocompatibility complex, class II, DR beta 3 & HLA-DRB3 & $6 \mathrm{p} 21.3$ \\
\hline 209835_x_at & 1.64 & 0.04319 & $\begin{array}{l}\text { CD44 antigen (homing function and Indian blood } \\
\text { group system) }\end{array}$ & CD44 & $11 \mathrm{p} 13$ \\
\hline 200745_s_at & 1.61 & 0.00057 & $\begin{array}{l}\text { Guanine nucleotide binding protein ( } \mathrm{G} \text { protein), } \\
\text { beta polypeptide } 1\end{array}$ & GNB1 & $1 \mathrm{p} 36.33$ \\
\hline 207616_s_at & 1.60 & 0.03284 & TRAF family member-associated NFKB activator & TANK & 2q24-q31 \\
\hline 209331 s_at & 1.59 & 0.00476 & MAX protein & MAX & $14 \mathrm{q} 23$ \\
\hline 200746_s_at & 1.56 & 0.00108 & $\begin{array}{l}\text { Guanine nucleotide binding protein (G protein), beta } \\
\text { polypepide } 1\end{array}$ & GNB1 & $1 \mathrm{p} 36.33$ \\
\hline 209586 s at & 1.55 & 0.02552 & TcD37 homolog & HTCD37 & $1 q 21$ \\
\hline 222294_s_at & 1.54 & 0.03711 & RAB27A, member RAS oncogene family & RAB27A & $15 q 15-q 21.1$ \\
\hline 200084_at & 1.50 & 0.03447 & Small acidic protein & SMAP & $11 \mathrm{p} 15.2$ \\
\hline 204396_s_at & 1.50 & 0.00192 & G protein-coupled receptor kinase 5 & GRK5 & 10q24-qter \\
\hline 204373_s_at & 1.48 & 0.01338 & Centrosome-associated protein 350 & CAP350 & 1p36.13-q41 \\
\hline 201061 s at & 1.48 & 0.03523 & Stomatin & STOM & $9 q 34.1$ \\
\hline 218284_at & 1.48 & 0.04873 & DKFZP586N0721 protein & DKFZP586N0721 & $15 q 22.31$ \\
\hline 202698_x_at & 1.46 & 0.04149 & Cytochrome- $c$ oxidase subunit IV isoform 1 & COX4I1 & 16q22-qter \\
\hline 201560_at & 1.44 & 0.04648 & Chloride intracellular channel 4 & CLIC4 & $1 \mathrm{p} 36.11$ \\
\hline 206544_x_at & 1.43 & 0.03723 & $\begin{array}{l}\text { SWI/SNF related, matrix associated, actin dependent } \\
\text { regulator of chromatin, subfamily a2 }\end{array}$ & SMARCA2 & $9 \mathrm{p} 22.3$ \\
\hline 202061_s_at & 1.42 & 0.00889 & sel-1 suppressor of lin-12-like (C. elegans) & SEL1L & $14 \mathrm{q} 24.3-\mathrm{q} 31$ \\
\hline 202840_āt & 1.41 & 0.01641 & $\begin{array}{l}\text { TAF15 RNA polymerase II, TATA box binding protein } \\
\text { (TBP)-associated factor, } 68 \mathrm{kDa}\end{array}$ & TAF15 & 17q11.1-q11.2 \\
\hline 204735_at & 1.40 & 0.00917 & $\begin{array}{l}\text { Phosphodiesterase 4A, cAMP-specific } \\
\text { (phosphodiesterase E2 dunce homolog, Drosophila) }\end{array}$ & PDE4A & $19 \mathrm{p} 13.2$ \\
\hline 204070_at & 1.39 & 0.01290 & Retinoic acid receptor responder (tazarotene induced) 3 & RARRES3 & $11 q 23$ \\
\hline 208938_at & 1.39 & 0.00493 & Papillary renal cell carcinoma (translocation-associated) & ) PRCC & $1 \mathrm{q} 21.1$ \\
\hline 201144_s_at & 1.38 & 0.02715 & $\begin{array}{l}\text { Eukaryotic translation intiation factor } 2 \text {, subunit } 1 \\
\text { alpha, } 35 \mathrm{kDa}\end{array}$ & EIF2S1 & $14 \mathrm{q} 24.1$ \\
\hline 205049 s at & 1.38 & 0.03527 & CD79A antigen (immunoglobulin-associated alpha) & CD79A & $19 q 13.2$ \\
\hline 200605_s_at & 1.37 & 0.01436 & $\begin{array}{l}\text { Protein kinase, cAMP-dependent regulatory, type } 1 \text {, } \\
\text { alpha (tissue specific extinguisher } 1 \text { ) }\end{array}$ & PRKAR1A & $17 q 23-q 24$ \\
\hline 200885_at & 1.36 & 0.04139 & Ras homolog gene family, member $\mathrm{C}$ & $\mathrm{RHOC}$ & $1 \mathrm{p} 13.1$ \\
\hline 204489_s_at & 1.33 & 0.01981 & $\begin{array}{l}\text { CD44 antigen (homing function and Indian blood } \\
\text { group system) }\end{array}$ & CD44 & $11 \mathrm{p} 13$ \\
\hline 214271_x_at & 1.33 & 0.02639 & Ribosomal protein L12 & RPL12 & $9 q 34$ \\
\hline 212014_x_at & 1.33 & 0.02870 & $\begin{array}{l}\text { CD44 antigen (homing function and Indian blood } \\
\text { group system) }\end{array}$ & CD44 & $11 \mathrm{p} 13$ \\
\hline 212352_s_at & 1.31 & 0.04363 & Transmembrane trafficking protein & TMP21 & $14 q 24.3$ \\
\hline 214836_x_at & 1.31 & 0.04004 & $\begin{array}{l}\text { Kappa-immunoglobulin germline pseudogene } \\
\text { (Chr22.4) variable region (subgroup V kappa II) }\end{array}$ & - & $2 \mathrm{p} 11.2$ \\
\hline 221737_at & 1.31 & 0.03167 & $\begin{array}{l}\text { Guanine nucleotide binding protein } \\
\text { (G protein) alpha } 12\end{array}$ & GNA12 & $7 \mathrm{p} 22-\mathrm{p} 21$ \\
\hline \multicolumn{6}{|c|}{ Decreased expression } \\
\hline $214022 \mathrm{~s}$ at & -1.68 & 0.01385 & Interferon induced transmembrane protein $1(9-27)$ & IFITM1 & $11 \mathrm{p} 15.5$ \\
\hline 201662_s_at & -1.64 & 0.03130 & Acyl-CoA synthetase long-chain family member 3 & ACSL3 & 2q34-q35 \\
\hline 208800_at & -1.60 & 0.04517 & Signal recognition particle $72 \mathrm{kDa}$ & SRP72 & $4 \mathrm{q} 11$ \\
\hline 201523_x_at & -1.54 & 0.01262 & $\begin{array}{l}\text { Ubiquitin-conjugating enzyme E2N (UBC13 homolog } \\
\text { yeast) }\end{array}$ & UBE2N & $12 \mathrm{q} 22$ \\
\hline $205099 \mathrm{~s}$ at & -1.47 & 0.02248 & Chemokine (C-C motif) receptor 1 & CCR1 & $3 \mathrm{p} 21$ \\
\hline 219557_s_al & -1.45 & 0.03653 & Nuclear receptor interacting protein 3 & NRIP3 & $11 \mathrm{p} 15.3$ \\
\hline 218852_at & -1.44 & 0.04879 & Chromosome 14 open reading frame 10 & C14orf10 & $14 \mathrm{q} 13.2$ \\
\hline 201524_x_at & -1.42 & 0.03537 & $\begin{array}{l}\text { Ubiquitin-conjugating enzyme E2N (UBC13 homolog, } \\
\text { yeast) }\end{array}$ & UBE2N & $12 \mathrm{q} 22$ \\
\hline 206689_s_at & -1.41 & 0.04480 & Transcription factor binding to IGHM enhancer 3 & TFE3 & Xp11.22 \\
\hline
\end{tabular}


TABLE II. (Continued)

\begin{tabular}{|c|c|c|c|c|c|}
\hline Probe ID & Fold change & $P$-value & Gene title & Symbol & Location \\
\hline 205382_s_at & -1.38 & 0.03956 & D component of complement (adipsin) & $\mathrm{DF}$ & $19 \mathrm{p} 13.3$ \\
\hline 212414_s_at & -1.37 & 0.03062 & Septin 6 & SEPT6 & $\mathrm{Xq} 25$ \\
\hline $218543 \mathrm{~s}$ at & -1.35 & 0.04712 & Zinc finger $\mathrm{CCCH}$ type domain containing 1 & ZC3HDC1 & $7 q 34$ \\
\hline 212658_at & -1.34 & 0.04834 & Lipoma HMGIC fusion partner-like 2 & LHFPL2 & $5 \mathrm{q} 14.1$ \\
\hline $215424^{-} \mathrm{s}$ at & -1.33 & 0.00794 & SKI interacting protein & SKIIP & $14 q 24.3$ \\
\hline 217960_s_at & -1.33 & 0.03531 & $\begin{array}{l}\text { Translocase of outer mitochondrial membrane } 22 \\
\text { homolog (yeast) }\end{array}$ & TOMM22 & $22 q 12-q 13$ \\
\hline 203077 s at & -1.28 & 0.04364 & SMAD, mothers against DPP homolog 2 (Drosophila) & SMAD2 & $18 \mathrm{q} 21.1$ \\
\hline 202164_s_at & -1.28 & 0.03718 & CCR4-NOT transcription complex, subunit 8 & CNOT8 & $5 q 31-q 33$ \\
\hline $218753^{-}$at & -1.28 & 0.03344 & Hypothetical protein FLJ10307 & FLJ10307 & $1 \mathrm{p} 35.2$ \\
\hline 203055_s_at & -1.28 & 0.02857 & Rho guanine nucleotide exchange factor (GEF) 1 & ARHGEF1 & $19 q 13.13$ \\
\hline $212397^{-}$at & -1.28 & 0.02452 & Radixin & RDX & $11 \mathrm{q} 23$ \\
\hline 221490_at & -1.28 & 0.04365 & Ubiquitin associated protein 1 & UBAP1 & $9 \mathrm{p} 22-\mathrm{p} 21$ \\
\hline 212766_s_at & -1.26 & 0.04957 & Hypothetical protein FL12671 & FLJ12671 & $1 \mathrm{q} 23.1$ \\
\hline 201083_s_at & -1.26 & 0.02615 & BCL2-associated trancription factor & BCLAF1 & $6 \mathrm{q} 22-\mathrm{q} 23$ \\
\hline 209704_āt & -1.25 & 0.04701 & $\begin{array}{l}\text { Likely ortholog of mouse metal response } \\
\text { element binding transcription factor } 2\end{array}$ & M96 & $1 \mathrm{p} 22.1$ \\
\hline 218214 at & -1.25 & 0.04535 & Hypothetical protein FLJ11773 & FLJ11773 & $12 q 13.13$ \\
\hline 201978_s_at & -1.25 & 0.04803 & KIAA0141 gene product & KIAA0141 & $5 \mathrm{q} 31.3$ \\
\hline 208811_s_at & -1.24 & 0.02519 & DnaJ (Hsp40) homolog, subfamily B, member 6 & DNAJB6 & $7 \mathrm{q} 36.3$ \\
\hline 218403 at & -1.24 & 0.03064 & Hypothetical protein HSPC132 & HSPC132 & $12 q 24.31$ \\
\hline 201856_s_at & -1.21 & 0.03464 & Zinc finger RNA binding protein & ZFR & $5 \mathrm{p} 13.3$ \\
\hline 201712 s at & -1.21 & 0.03245 & RAN binding protein 2 & RANBP2 & $2 q 12.3$ \\
\hline 220349_s_at & -1.21 & 0.01209 & Endo-beta-N-acetylglucosaminidase & FLJ21865 & $17 q 25.3$ \\
\hline 217956 s_at & -1.20 & 0.00290 & E-1 enzyme & MASA & $4 \mathrm{q} 21.3$ \\
\hline 217208_s_at & -1.19 & 0.04560 & Discs, large homolog 1 (Drosophila) & DLG1 & $3 q 29$ \\
\hline 202947_s_at & -1.19 & 0.02718 & Glycophorin C (Gerbich blood group) & GYPC & $2 q 14-q 21$ \\
\hline 204777_s_at & -1.18 & 0.00702 & Mal, T-cell differentiation protein & MAL & 2cen-q13 \\
\hline 212757_s_at & -1.17 & 0.04972 & $\begin{array}{l}\text { Calcium/calmodulin-dependent protein kinase } \\
\text { (CaM kinase) II gamma }\end{array}$ & CAMK2G & $10 \mathrm{q} 22$ \\
\hline 213560_at & -1.17 & 0.04758 & Growth arrest and DNA-damage-inducible, beta & GADD45B & $19 \mathrm{p} 13.3$ \\
\hline 218615_s_at & -1.16 & 0.00929 & Hypothetical protein FLJ10902 & FLJ10902 & $3 q 13.33$ \\
\hline 201966_āt & -1.15 & 0.04461 & $\begin{array}{l}\text { NADH dehydrogenase (ubiquinone) Fe-S protein } 2 \text {, } \\
49 \mathrm{kDa} \text { (NADH-coenzyme Q reductase) }\end{array}$ & NDUFS2 & $1 \mathrm{q} 23$ \\
\hline 216333_x_at & -1.15 & 0.02708 & Tenascin XB & TNXB & $6 \mathrm{p} 21.3$ \\
\hline
\end{tabular}

hybridized to the Human Genome U133A GeneChip ( ) (Affymetrix), washed and stained on a fluidics station (Affymetrix) according to the EukGE-WS2 protocol, and scanned using the G2500A Gene Array Scanner. The scan files were normalized using the Gene Chip Robust Multichip Analysis method [Irizarry et al., 2003].

Statistical changes in gene expression were determined in pairwise fashion using the Significance Analysis algorithm (GeneTraffic, Iobion). All of the transcript probes that were significantly changed $(P<0.05)$ were ranked by mean pairwise fold change. This was applied to both the entire genome for schizophrenia and bipolar disorder (Tables I and II, respectively) and each of the candidate genome regions (5q and $6 q$ ) (Table III). Notably, because of the relatively small number of sib-pairs used in the bipolar study, we present the top fold changes in the $6 q$ locus using a threshold of $P<0.10$ for this disorder.

\section{Prediction Classification}

From the lists of significantly changed genes, we also sought to derive a preliminary list of genes whose expression patterns might be useful as predictors of diagnosis. For this analysis, we used the Class Predictor algorithm (GeneSpring) to predict the value, or "class," of individual parameters in the set of samples. This was done using both the Euclidian nearest neighbor method and support vector machine (SVM) method. The genes with the highest predictive power in our dataset were ranked by their predictive strength (Table IV). Importantly, we point out that because we used the methods that require defining a training set, the list we present still requires validation in an independent cohort.

\section{Gene Group Analysis}

We determined the relevant biological pathway information in our expression data using custom-written software [PathStat; see Middleton et al., 2004] to extract distributions of differential expression ratios for functionally related groups of transcripts using publicly curated databases. These databases included the different groups of the Gene Ontology database (http://us.expasy.org/cgi-bin/enzyme-search-cl), the Kyoto Encyclopedia of Genes and Genomes database (http:// www.genome.ad.jp/kegg/pathway.html), the Enzyme Commission database (http://us.expasy.org/cgi-bin/enzyme-search-cl), and the Protein Family (pFam) database (http://www.sanger. ac.uk/Software/Pfam/search.shtml). Lists of the specific probes on the Affymetrix U133A GeneChip that belong to each of these groupings are available in a single annotated file from the Affymetrix NetAffx website (http://www.affymetrix.com/ support/technical/byproduct.affx?product=hgu133-20). To perform the pathway analyses, the scaled and normalized gene expression level was first calculated using robust multi-chip analysis (RMA), and then the expression level of each gene in the affected pairs (BP or SCZ subjects) was compared to the corresponding expression level of the same gene in the matched 
TABLE III. Changed Individual Probesets in Loci of Interest

\begin{tabular}{|c|c|c|c|c|c|}
\hline Probe ID & $\begin{array}{l}\text { Fold } \\
\text { change }\end{array}$ & $P$-value & Gene title & Symbol & Location \\
\hline \multicolumn{6}{|c|}{ Schizophrenia $5 q$ linkage region $(P<0.05)$} \\
\hline 201743 at & 2.53 & 0.00108 & CD14 antigen & CD14 & $5 \mathrm{q} 31.1$ \\
\hline 201694_s_at & 1.74 & 0.01116 & Early growth response 1 & EGR1 & $5 \mathrm{q} 31.1$ \\
\hline $210844 \mathrm{x}$ at & 1.63 & 0.00142 & Catenin (cadherin-associated protein), alpha 1, $102 \mathrm{kDa}$ & CTNNA 1 & $5 q 31$ \\
\hline 200765_x_at & 1.62 & 0.00056 & Catenin (cadherin-associated protein), alpha 1, $102 \mathrm{kDa}$ & CTNNA 1 & $5 q 31$ \\
\hline 203218 at & 1.59 & 0.00311 & Mitogen-activated protein kinase 9 & MAPK9 & $5 q 35$ \\
\hline 217840 at & 1.48 & 0.01072 & DEAD (Asp-Glu-Ala-Asp) box polypeptide 41 & DDX41 & $5 \mathrm{q} 35.3$ \\
\hline 214658_at & 1.46 & 0.03732 & CGI-109 protein & CGI-109 & $5 \mathrm{q} 23.1$ \\
\hline $201506^{-}$at & 1.46 & 0.02373 & Transforming growth factor, beta-induced, $68 \mathrm{kDa}$ & TGFBI & $5 q 31$ \\
\hline 205896_at & 1.44 & 0.00904 & Solute carrier family 22 (organic cation transporter), member 4 & SLC22A4 & $5 \mathrm{q} 31.1$ \\
\hline 202360_at & 1.36 & 0.00170 & Mastermind-like 1 (Drosophila) & MAML1 & $5 q 35$ \\
\hline $202227^{-} \mathrm{s}$ at & 1.36 & 0.00387 & Bromodomain containing 8 & BRD8 & $5 q 31$ \\
\hline 220495_s_at & 1.34 & 0.01182 & Chromosome 5 open reading frame 14 & C5orf14 & $5 \mathrm{q} 31.2$ \\
\hline $212900^{-}$at & 1.33 & 0.03403 & SEC24 related gene family, member A (S. cerevisiae) & SEC24A & $5 \mathrm{q} 31.2$ \\
\hline 212137_at & 1.31 & 0.01715 & Likely ortholog of mouse Ia related protein & LARP & $5 \mathrm{q} 33.2$ \\
\hline \multicolumn{6}{|c|}{ Bipolar $6 \bar{q}$ linkage region $(P<0.10)$} \\
\hline 208623 s at & 2.57 & 0.08125 & Villin 2 (ezrin) & VIL2 & $6 \mathrm{q} 25.2-\mathrm{q} 26$ \\
\hline 210105_s_at & 2.01 & 0.08039 & FYN oncogene related to SRC, FGR, YES & FYN & $6 q 21$ \\
\hline $216033^{-}$sat & 1.66 & 0.09324 & FYN oncogene related to SRC, FGR, YES & FYN & $6 q 21$ \\
\hline 212265_at & 1.41 & 0.09018 & Quaking homolog, KH domain RNA binding (mouse) & QKI & $6 q 26-27$ \\
\hline 201915 at & 1.17 & 0.02738 & SEC63-like (S. cerevisiae) & SEC63 & $6 q 21$ \\
\hline $221311^{-} \mathrm{x}$ at & 1.17 & 0.09196 & Hypothetical protein dJ122O8.2 & DJ12208.2 & 6q14.2-q16.1 \\
\hline 210156_s_at & 1.16 & 0.02719 & Protein-L-isoaspartate (D-aspartate) O-methyltransferase & PCMT1 & $6 q 24-q 25$ \\
\hline $204207^{-}$s at & 1.14 & 0.07257 & RNA guanylyltransferase and $5^{\prime}$-phosphatase & RNGTT & $6 q 16$ \\
\hline 205116_āt & 1.11 & 0.05556 & Laminin, alpha 2 (merosin, congenital muscular dystrophy) & LAMA2 & $6 q 22-q 23$ \\
\hline 215904_at & 1.09 & 0.06463 & $\begin{array}{l}\text { Myeloid/lymphoid or mixed-lineage leukemia (trithorax } \\
\text { homolog, Drosophila) }\end{array}$ & MLLT4 & $6 \mathrm{q} 27$ \\
\hline 206005_s_at & 1.08 & 0.07908 & Chromosome 6 open reading frame 84 & C6orf84 & $6 q 15$ \\
\hline 217399_s_at & 1.03 & 0.03835 & Forkhead box O3A & FOXO3A & $6 q 21$ \\
\hline 209608_s_at & -1.19 & 0.09159 & $\begin{array}{l}\text { Acetyl-coenzyme A acetyltransferase } 2 \text { (acetoacetyl Coenzyme } \\
\text { A thiolase) }\end{array}$ & ACAT2 & $6 \mathrm{q} 25.3-\mathrm{q} 26$ \\
\hline 201083_s_at & -1.26 & 0.02615 & BCL2-associated transcription factor 1 & BCLAF1 & $6 q 22-q 23$ \\
\hline
\end{tabular}

control subject. This ratio was generated only if the expression level in at least one of the samples was greater than the median RMA normalized signal intensity of the dataset (computed signal $\sim 12$ or higher). PathStat then compiled the gene-bygene expression ratios for each functional group, as well as all the genes on the chip, and calculated a $t$ statistic for the group that was proportional to the number of standard deviations that group's expression had shifted in the affected subject pair, adjusted for the number of transcripts in each group. Gene group ratios were only generated if an average of at least three transcript ratios were computed in each group [Middleton et al., 2002, 2004]. For each disease, we present the omnibus data (all 5 or 33 subject pairs combined) for this report. This highly conservative method enables one to detect large-scale coordinated changes in functional gene group expression in complex treatment paradigms or disease states. In the present analysis, PathStat mapped our expression data to a total of more than 3,000 separate publicly curated pathways. Tables of the top 25 increased and decreased gene group alterations in each disorder were generated.

\section{Cytogenomics}

In addition to the functional gene groups, we also utilized a new approach for mining and mapping expression changes within the context of cytogenetic loci, an approach we term "cytogenomics." For example, single megabase bins generally contain approximately 8-12 gene probes of which approximately half will be expressed in the blood or brain of human subjects. Each of these megabase bins was treated as a gene group cluster and the pairwise and genewise differences in expression used to create high-density cytogenomic $\mathrm{Z}$ score plots (Fig. 1). These Z score plots were compared directly with the NPL Z score plot and a Chi Square plot derived from the linkage and association analyses of schizophrenia and bipolar disorder. Two examples of the utility of this approach are provided (Fig. 2). To perform the genome-wide association analysis, we used Varia (Silicon Genetics) to construct a haplotype map (E-M algorithm) of the complete set of 25 bipolar families genotyped with the Affymetrix Human Mapping Assay Xba 141 [see Middleton et al., 2004]. A preliminary genome-wide family-based Transmission Disequilibrium Test (TDT) was performed and the most significant results for the entire genome were listed (Table VIII). Moreover, the Chi Square values from this analysis were overlaid with the expression and linkage plots for chromosome $6 q$ (Fig. 2).

\section{Microarray Validation With Quantitative Real-Time RT-PCR (qRT-PCR)}

Validation of selected changes in expression was performed using quantitative real-time RT-PCR (qRT-PCR), using RNA from 19 of the 33 schizophrenia sibpairs and all 5 bipolar sibpairs for whom sufficient RNA was available. Primer sequences for each gene of interest were designed using Primer3 software, and are available upon request. For the RT reactions, equal amounts of total RNA (250 ng) from each sample were reverse transcribed (Superscript II protocol) with an oligo dT primer prior to quantitative PCR according to the 
TABLE IV. Genes With Most Power for Distinguishing Affected and Control Subjects

\begin{tabular}{|c|c|c|c|c|}
\hline Probe ID & $\begin{array}{l}\text { Pred } \\
\text { strength }\end{array}$ & Map & Product & LOI \\
\hline 201253_s_at & 34.51 & $16 q 13$ & $\begin{array}{l}\text { CDP-diacylglycerol-inositol 3-phosphatidyltransferase } \\
\text { (phosphatidylinositol synthase) }\end{array}$ & \\
\hline 207850 at & 34.51 & $4 q 21$ & Chemokine (C-X-C motif) ligand 3 & \\
\hline 205098_at & 33.18 & $3 \mathrm{p} 21$ & Chemokine (C-C motif) receptor 1 & \\
\hline 204524_at & 30.9 & $16 \mathrm{p} 13.3$ & 3-Phosphoinositide dependent protein kinase-1 & \\
\hline 221732 at & 30.9 & $17 \mathrm{q} 25.3$ & Ectonucleoside triphosphate diphosphohydrolase 8 & \\
\hline 203333_at & 30.9 & $1 \mathrm{q} 22$ & Kinesin-associated protein 3 & \\
\hline 50374 at & 30.9 & $17 \mathrm{q} 25.3$ & Hypothetical protein LOC339229 & \\
\hline 20268̄﹎s_at & 30.9 & $3 \mathrm{p} 21.3$ & Ubiquitin specific protease 4 (proto-oncogene) & \\
\hline $221203 \mathrm{~s}$ at & 30.9 & $3 q 27.3$ & Hypothetical protein FLJ10201 & \\
\hline 220046 s at & 30.9 & $3 q 26.1$ & Cyclin L1 & \\
\hline 213708_s_at & 29.97 & $17 q 21.1$ & Transcription factor-like 4 & \\
\hline $2007655^{-}$at & 29.97 & $5 q 31.2$ & Catenin (cadherin-associated protein), alpha 1, $102 \mathrm{kDa}$ & $\leftarrow$ \\
\hline 200919_āt & 29.36 & $1 \mathrm{p} 34.3$ & Polyhomeotic-like 2 (Drosophila) & \\
\hline 221983_at & 29.36 & $2 \mathrm{q} 36.2$ & Chromosome 2 open reading frame 17 & \\
\hline 212265 at & 29.25 & $6 q 26-q 27$ & Quaking homolog, KH domain RNA binding (mouse) & $\leftarrow$ \\
\hline 221355_at & 29.25 & 2q33-q34 & Cholinergic receptor, nicotinic, gamma polypeptide & \\
\hline $200745 \mathrm{~s}$ at & 29.25 & 1p36.33 & Guanine nucleotide binding protein ( $\mathrm{G}$ protein), beta polypeptide 1 & \\
\hline 204446_s_at & 29.25 & $10 \mathrm{q} 11.2$ & Arachidonate 5-lipoxygenase & \\
\hline 222028_at & 29.25 & $19 \mathrm{q} 13.2$ & Zinc finger protein 45 (a Kruppel-associated box (KRAB) domain polypeptide) & \\
\hline $222103^{-}$at & 29.25 & $12 q 13.2$ & Activating transcription factor 1 & \\
\hline 208715_at & 29.25 & $1 \mathrm{q} 22-\mathrm{q} 25$ & Putative membrane protein & \\
\hline $218652^{-} \mathrm{s}$ at & 29.25 & $4 \mathrm{p} 16.3$ & Hypothetical protein FLJ20265 & \\
\hline 205424_āt & 28.06 & $17 q 21.2$ & ProSAPiP2 protein & \\
\hline 208732_at & 28.06 & $8 \mathrm{q} 11.23$ & RAB2, member RAS oncogene family & \\
\hline $204208^{-}$at & 28.06 & $6 q 16$ & RNA guanylyltransferase and $5^{\prime}$-phosphatase & $\leftarrow$ \\
\hline 204336_s_at & 28.06 & $20 \mathrm{q} 13.3$ & Regulator of G-protein signaling 19 & \\
\hline 211572_s_at & 28.06 & $20 \mathrm{p} 13$ & Solute carrier family 23 (nucleobase transporters), member 2 & \\
\hline $216042^{-}$at & 28.06 & 1p36.2 & Tumor necrosis factor receptor superfamily, member 25 & \\
\hline 201632_at & 28.06 & $12 q 24.31$ & Eukaryotic translation initiation factor $2 \mathrm{~B}$, subunit 1 alpha, $26 \mathrm{kDa}$ & \\
\hline 211574_s_at & 28.06 & $1 \mathrm{q} 32$ & $\begin{array}{l}\text { Membrane cofactor protein (CD46, trophoblast-lymphocyte } \\
\text { cross-reactive antigen) }\end{array}$ & \\
\hline 212626_x_at & 27.61 & $14 q 11.1$ & Heterogeneous nuclear ribonucleoprotein $\mathrm{C}$ (C1/C2) & \\
\hline 207943_x_at & 27.61 & $6 q 24-q 25$ & Pleiomorphic adenoma gene-like 1 & $\leftarrow$ \\
\hline 218195_at & 27.61 & $6 q 25.1$ & Chromosome 6 open reading frame 211 & $\leftarrow$ \\
\hline $221204^{-} \mathrm{s}$ at & 11.9 & $10 \mathrm{q} 22$ & Cartilage acidic protein 1 & \\
\hline 208289_s_at & 11.2 & $11 \mathrm{q} 24$ & Etoposide induced 2.4 mRNA & \\
\hline 210574_s_at & 10.06 & 1p35-p34 & Nuclear distribution gene C homolog (A. nidulans) & \\
\hline $217414 \mathrm{x}^{-}$at & 9.77 & $16 \mathrm{p} 13.3$ & Hemoglobin, alpha 2 & \\
\hline 206649_s_at & 9.572 & $\mathrm{Xp} 11.22$ & Transcription factor binding to IGHM enhancer 3 & \\
\hline 201083 s at & 9.572 & $5 q 23.3$ & BCL2-associated transcription factor 1 & $\leftarrow$ \\
\hline 202711_ā̄ & 9.572 & $\mathrm{Xq12}$ & Ephrin-B1 & \\
\hline 222048_at & 9.572 & $22 q 11.23$ & Adrenergic, beta, receptor kinase 2 & \\
\hline 218753 at & 9.572 & $1 \mathrm{p} 35.3$ & Hypothetical protein FLJ10307 & \\
\hline 209331_s_at & 9.572 & $14 \mathrm{q} 23$ & MAX protein & \\
\hline 209889_at & 9.13 & $10 \mathrm{q} 24.2$ & SEC31-like 2 (S. cerevisiae) & \\
\hline 204482_at & 9.13 & $22 q 11.21$ & Claudin 5 (transmembrane protein deleted in velocardiofacial syndrome) & \\
\hline 214487_s_at & 9.13 & $3 q 25.2$ & RAP2B, member of RAS oncogene family & \\
\hline $201382^{-}$at & 9.13 & $1 \mathrm{q} 24-\mathrm{q} 25$ & Siah-interacting protein & \\
\hline 209902_at & 9.13 & $3 q 22-q 24$ & Ataxia telangiectasia and Rad3 related & \\
\hline 217826_s_at & 9.13 & $6 q 16.1$ & Ubiquitin-conjugating enzyme E2, J1 (UBC6 homolog, yeast) & $\leftarrow$ \\
\hline 204070_at & 9.13 & $11 \mathrm{q} 23$ & Retinoic acid receptor responder (tazarotene induced) 3 & \\
\hline
\end{tabular}

LOI, locus of interest based on this population for schizophrenia or bipolar disorder.

standard TaqMan protocol (Applied Biosystems) using SYBRGreen I dye for amplicon detection with an ABI-7000 Real Time Sequence Detection System (Applied Biosystems). Statistical analysis was performed using a pairwise repeated measures ANOVA comparing the difference in the number of cycles to threshold $(\Delta \mathrm{Ct})$ between each target gene and alpha tubulin. Group differences were calculated by determining the mean pairwise difference in the delta $\mathrm{Ct}$ values per subject group (the $\Delta \Delta \mathrm{Ct}$ ), and a fold change calculated according to the formula, Fold change $=2^{-\Delta \Delta \mathrm{Ct}}$

\section{RESULTS \\ Sib-Pair Analyses}

Global significance analysis. Of the 22,283 probe sets on the array, in a strict pairwise analysis with the RMA normalized data, more than 2,000 genes showed significant changes in expression in our schizophrenia sib-pairs and 248 genes showed significant changes in expression in our much smaller set of bipolar sib-pair data $(P<0.05)$. Given the larger number of samples used in the schizophrenia analysis, 


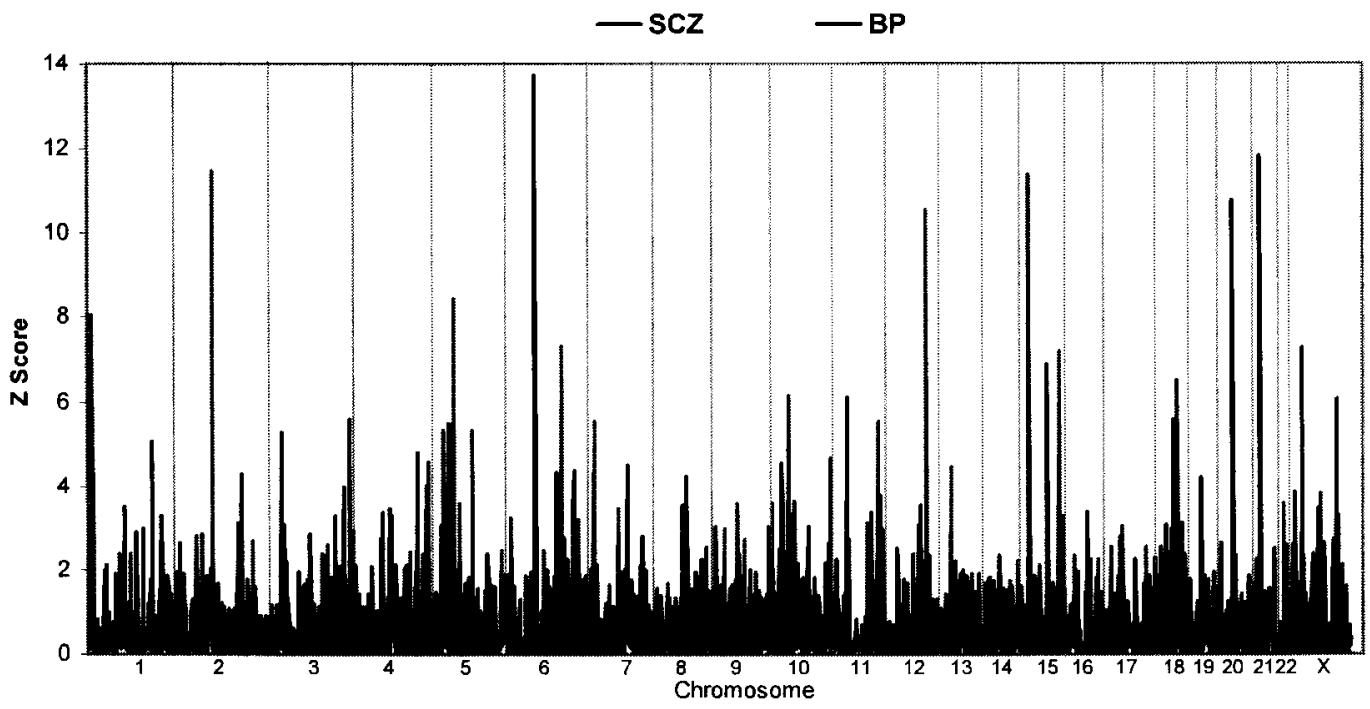

Fig. 1. Cytogenomic plot of expression abnormalities by MB. To generate this map, the pairwise differential expression ratio distribution of all expressed transcripts within $1 \mathrm{MB}$ proximity was determined, and the relative shift in this ratio distribution that compared the entire genome was calculated (as a Z score). For simplification, only the absolute value of the $\mathrm{Z}$ score is shown for each disorder. We note that SCZ and BP data do not display much similarity in their cytogenomic patterns.

implementing a multiple testing correction (BenjaminiHochberg) still produced a list of approximately 300 genes with significant changes in expression. However, because such a correction in $P$-values was not possible with the much smaller bipolar dataset, we chose to present purely uncorrected $P$-values in this report.

The 40 genes with the most robust increases and decreases in expression among those that were significantly affected are shown for each disorder (Tables I and II). While the limited sample size does not allow us to make specific comments on each of the genes in these tables, we have decided to present these data in order for other groups that may be working on similar efforts to be able to compare (and potentially combine) their findings with ours. We do point out that several of the genes with the most significant changes in expression did not exhibit large enough alterations to be included in these tables, which are based purely on fold changes.

Targeted significance analysis. We identified 729 transcript probes on the U133A GeneChip that were localized to $5 q$ for use in analyzing our SCZ sib-pairs and 431 transcripts on $6 q$ that were used to analyze expression in our BP sib-pairs. The 14 genes showing the largest fold changes (increases or decreases) at each locus were shown using a $P$-value threshold of 0.05 for schizophrenia and 0.10 for bipolar disorder (Table III).

Prediction classification. We used the Class Predictor Algorithm to identify those genes with the greatest potential diagnostic utility in schizophrenia and bipolar disorder in this population. After optimization, the nearest neighbor algorithm produced a list of 35 transcripts with approximately 95\% accuracy. Overall, 70 of 76 subjects were correctly classified as a control, BP or SCZ subject based on sib-pair expression differences, with four subjects misclassified and two subjects not classified. The SVM method obtained $100 \%$ accuracy with as few as 10 genes. The list of transcripts in both of these respective classifier lists was nearly identical. For simplicity, we present the top 50 predictor genes, ranked by their predictive strength according to the SVM algorithm (Table IV).

Gene group analysis. We assessed the expression patterns of all publicly curated functional pathways that could be mapped to the U133A GeneChip content. This analysis of more than 3,000 unique transcript collections revealed a set of gene groups with robust changes in expression in each disorder (Table V). Extending this analysis to include groups of genes located at the same physical position (in 1-MB bins), indicated fairly strong expression changes in a number of key loci in each disorder (Table VI). Importantly, we note that the Z scores for the top affected loci in each disorder were not correlated in the $\mathrm{BP}$ and SCZ datasets.

Cytogenomic mapping of expression abnormalities. The binning of the data used in the Gene Group Analysis allowed us to create $\mathrm{Z}$ score maps of the pairwise expression changes in our datasets, which we plotted for comparative purposes in a manner similar to a whole genome screen (Fig. 1). We point out that this figure revealed considerably different cytogenomic profiles for these two disorders. For illustrative purposes, we have also chosen to display the potential overlap of genetic and functional genomic signals on chromosomes $5 q$ for schizophrenia and $6 q$ for bipolar disorder (Fig. 2). This side by side analysis revealed a fair amount of overlap in the genetic linkage, association, and functional genomic results as was suggested by the data (Table VI).

Family-based association. Analysis of haplotype-based TDT performed by Varia using the 25 bipolar family dataset revealed a number of genomic regions with nominally significant linkage disequilibrium (Table VII). Despite the limits of the resolution of the SNP map used to generate haplotypes $(\sim 210 \mathrm{~KB})$, it is notable that several of the haplotype blocks highlighted are located in proximity to both the $6 \mathrm{q}$ linkage peak and the gene expression $\mathrm{Z}$ score peaks. We have begun to use higher density SNP genotyping arrays to achieve greater resolution and explore these intriguing findings in more detail.

Validation of selected genes with real-time quantitative RT-PCR. In our PBL sib-pairs, we examined the expression of multiple individual transcripts with an independent technique to confirm the accuracy and reliability of the microarray data. Due to limited RNA, only 19 of the original 33 schizophrenic sib-pairs (but all 5 bipolar sib-pairs) were used in these studies. Several genes with increased and decreased expression, including the Sensory and Motor Neuron Derived Factor (SMDF) variant of Neuregulin 1 (NRG1), Transcription factor-like 4 (TCFL4), Serotonin Receptor Type 4 (5HT4), and A Disintegrin and Matrix Metalloproteinase 19 (ADAM19) were all confirmed as showing the same (or greater) amount of 


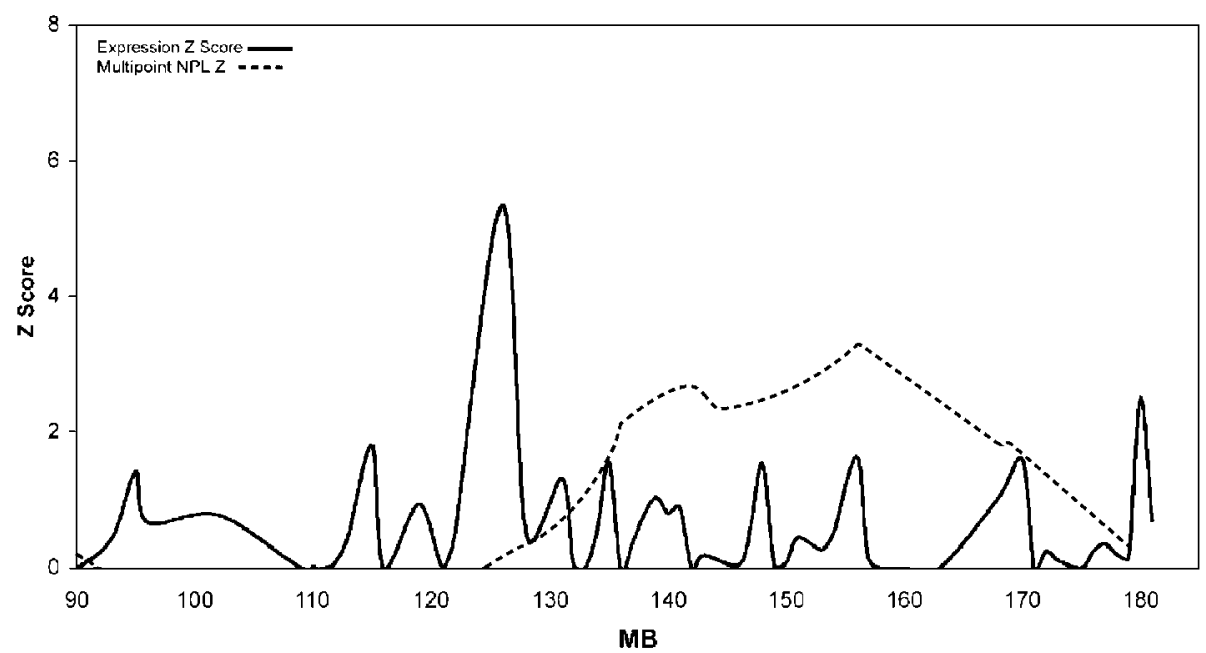

Chromosome 6q Genomic/Genetic Signals - Bipolar Disorder

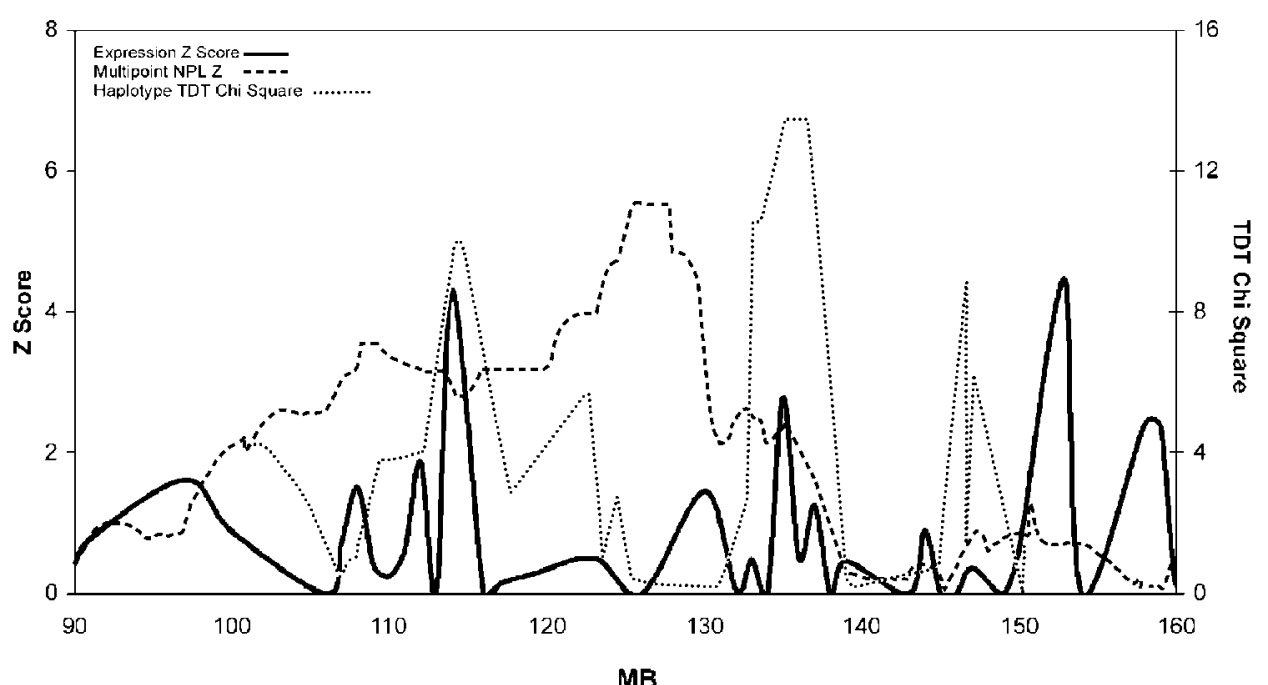

Fig. 2. Regions of putative genetic and functional genomic convergence. Top, Nonparametric linkage results in families used in a medium resolution microsatellite scan of chromosome 5q [Sklar et al., 2004]. Data have been replotted in physical (MB) coordinates (dashed line). The pairwise gene expression data from 33 discordant sib-pairs from these families were used to generate an expression $\mathrm{Z}$ score plot through the same region (solid line). Bottom, Families with $6 \mathrm{q} 22$ linkage from the 25 used in a previous genomewide screen [dashed line; Middleton et al., 2004] were analyzed with a highdensity SNP genotyping array. The data from this same dataset were used to create a whole genome haplotype map and test for TDT. The Chi Square values obtained in the TDT analysis for chromosome $6 q$ are illustrated (dotted line). Five age- and gender-matched discordant sib-pairs from these families were used for leukocyte expression analysis in the current study (expression $\mathrm{Z}$ score as solid line). We note that the peak expression $\mathrm{Z}$ scores in both schizophrenia and bipolar disorder are located near peak linkage regions, although the positions of the TDT peaks show even more similarity with the expression $\mathrm{Z}$ score peaks. change seen in the array data (Table VIII). A fifth transcript (Synaptobrevin 2, or VAMP2) was confirmed as showing the same direction of change as the array data, but the $P$-value did not attain significance (Table VIII). Moreover, other genes that did not change in the array data were also confirmed, including at least two housekeeping genes-alpha tubulin and RNA Polymerase II (Table VIII). Overall, the mean pairwise fold changes for these seven transcripts were highly correlated in the array and PCR datasets $(\mathrm{R}=0.951)$.

Genes involved in presynaptic function in the brain are also altered in PBLs. Expression profiling of postmortem brain tissue in subjects with schizophrenia has revealed some commonly affected intracellular cascades, particularly those involving presynaptic secretory function [PSYN genes; see Mirnics et al., 2000]. In order to begin to address whether PBLs also share some of the same expression changes as postmortem brain, we searched for significant $(P<0.05)$ pairwise expression changes in the PSYN genes in our schizophrenia data. Interestingly, some 35 unique transcripts were found with such changes. Most of these involved small differences (less than 20\% mean pairwise changes). However, among the transcripts with $20 \%$ or greater increases in expression were synaptophysin-like protein (SYPL, +1.4fold), synaptosomal-associated protein, $23 \mathrm{kDa}$ (SNAP23, +1.4 -fold), N-ethylmaleimide-sensitive factor (NSF, +1.4fold), dynactin 3 (DCTN3, +1.4-fold), sorting nexin 2 (SNX2, 


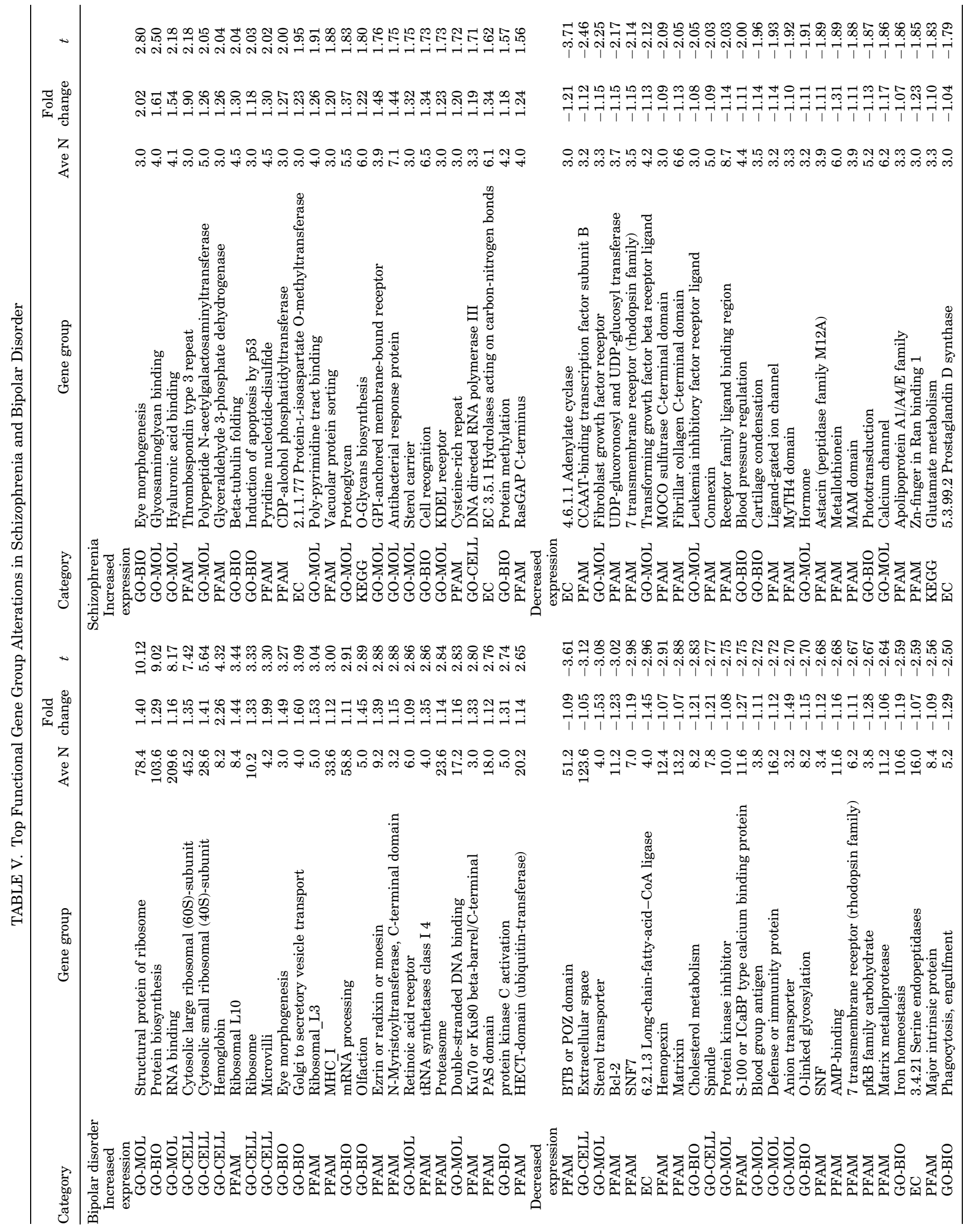


TABLE VI. Top Loci Expression Alterations in Schizophenia and Bipolar Disorder

\begin{tabular}{|c|c|c|c|c|c|c|c|c|c|}
\hline \multicolumn{5}{|c|}{ Bipolar disorder } & \multicolumn{5}{|c|}{ Schizophrenia } \\
\hline \multirow[b]{2}{*}{$\mathrm{Chr}$} & \multirow[b]{2}{*}{ MB } & \multicolumn{2}{|c|}{$\mathrm{Z}$ score } & \multirow{2}{*}{$\begin{array}{l}\mathrm{NPL}>2 \\
\pm 15 \mathrm{MB}\end{array}$} & \multirow[b]{2}{*}{$\mathrm{Chr}$} & \multirow[b]{2}{*}{$\mathrm{MB}$} & \multicolumn{2}{|c|}{$\mathrm{Z}$ score } & \multirow{2}{*}{$\begin{array}{l}\mathrm{NPL}>2 \\
\pm 15 \mathrm{MB}\end{array}$} \\
\hline & & $\mathrm{BP}$ & $\mathrm{SCZ}$ & & & & $\mathrm{BP}$ & $\mathrm{SCZ}$ & \\
\hline 6 & 52 & 13.72 & 0.08 & & 2 & 72 & 1.48 & 11.48 & \\
\hline 21 & 31 & 11.84 & 1.05 & & $1 \overline{5}$ & 37 & 2.31 & 11.38 & \\
\hline 20 & 23 & 10.78 & 0.03 & Y & 12 & 102 & 0.64 & 10.58 & \\
\hline $\mathrm{X}$ & 29 & 7.29 & 0.77 & & 12 & 103 & 0.07 & 8.58 & \\
\hline 15 & 68 & 6.87 & 2.39 & & 5 & 73 & 0.74 & 8.45 & \\
\hline 11 & 37 & 6.13 & 2.65 & Y & 1 & 7 & 1.19 & 8.08 & \\
\hline 18 & 45 & 5.59 & 0.62 & & 6 & 130 & 1.45 & 7.32 & $\mathrm{Y}$ \\
\hline 3 & 187 & 5.59 & 0.60 & & 15 & 86 & 0.80 & 7.19 & \\
\hline 10 & 36 & 5.07 & 6.15 & & 18 & 53 & 3.84 & 6.48 & \\
\hline 1 & 182 & 5.05 & 0.09 & & 10 & 36 & 5.07 & 6.15 & \\
\hline 4 & 160 & 4.83 & 0.00 & & $X$ & 128 & 0.75 & 6.07 & \\
\hline 10 & 134 & 4.70 & 1.77 & & 7 & 28 & 0.98 & 5.56 & \\
\hline 7 & 104 & 4.49 & 1.42 & & 11 & 123 & 4.04 & 5.55 & \\
\hline 6 & 153 & 4.37 & 1.18 & & 5 & 62 & 1.64 & 5.53 & \\
\hline 6 & 114 & 4.32 & 2.53 & $\mathrm{Y}$ & 5 & 126 & 0.25 & 5.34 & $\mathrm{Y}$ \\
\hline 2 & 162 & 4.28 & 0.70 & $\mathrm{Y}$ & 5 & 44 & 0.74 & 5.33 & \\
\hline 8 & 74 & 4.24 & 1.46 & & 3 & 24 & 2.31 & 5.30 & \\
\hline 19 & 39 & 4.20 & 0.17 & Y & 5 & 0 & 3.09 & 4.61 & \\
\hline 11 & 123 & 4.04 & 5.55 & & 10 & 27 & 0.75 & 4.55 & $\mathrm{Y}$ \\
\hline 3 & 174 & 3.98 & 0.15 & & 13 & 28 & 0.00 & 4.46 & \\
\hline 18 & 53 & 3.84 & 6.48 & & 5 & 68 & 1.73 & 4.13 & \\
\hline 11 & 129 & 3.77 & 1.35 & & 4 & 186 & 2.02 & 4.03 & \\
\hline 6 & 152 & 3.68 & 2.82 & & $\mathrm{X}$ & 14 & 0.51 & 3.85 & \\
\hline 8 & 67 & 3.56 & 0.38 & $\mathrm{Y}$ & $\mathrm{X}$ & 71 & 0.22 & 3.82 & \\
\hline 1 & 86 & 3.53 & 0.95 & & 4 & 157 & 2.64 & 3.69 & \\
\hline
\end{tabular}

Loci within 15 megabases (15 MB) of an NPL Z score $>2.0$ in this population are indicated for each disorder.

+1.3 -fold), vacuolar protein sorting 33B (VPS33B, +1.3 -fold), tyrosine 3-monooxygenase/tryptophan 5-monooxygenase activation protein, beta (YWHAB, +1.2-fold), and vesicle-associated membrane protein 4 (VAMP $4,+1.2$-fold). On the other hand, far fewer PSYN transcripts showed pairwise decreases in expression of this magnitude, with the notable exceptions of clathrin, heavy polypeptide (CLTC, -1.2-fold) and synaptojanin 2 (SYNJ2, -1.2-fold). These findings of increased expression of NSF, synaptophysin, and other related genes are actually opposite the findings reported in previous microarray studies of postmortem brain tissue. Taken together, these observations reinforce the potential power of PBL expression data to detect significant expression alterations of some of the same genes implicated by postmortem brain tissue studies, although the direction of change is not necessarily the same.

\section{DISCUSSION}

In this very preliminary study, we have explored the potential utility of gene expression data acquired from PBLs of subjects with schizophrenia or bipolar disorder and their discordant age- and gender-matched siblings. Specifically, we sought to: (1) identify those genes and functional gene groups that are the most affected in the disease (pathophysiogenomics); (2) evaluate candidate genes and gene regions for abnormal expression patterns that are correlated with known locations of genetic linkage or association in the same population; (3) identify genes with the greatest degree of diagnostic utility; (4) search for candidate genomic loci that might be involved in the primary disease pathogenesis; and (5) attempt to correlate specific SNP haplotypes with altered expression patterns. We briefly highlight some of our progress in each of these aims.

\section{Most Significantly Changed Genes in Schizophrenia and Bipolar Disorder}

It is not possible for us to review all of the single gene findings in our dataset within the context of this preliminary report. Thus, we have chosen to highlight a few of the observations that we believe have particular novelty or relate to the preexisting literature on schizophrenia, bipolar disorder, or brain function.

Schizophrenia. There were a number of genes among those with the most significant increases in expression that are known to be involved in immune and/or inflammatory function (e.g., CD14 antigen, chemokine receptor 1; Table I). Interestingly, however, we also detected a number of expression changes in genes that are known to be involved in brain development (e.g., alpha catenin, neuregulin 1 (SMDF variant)). The single most significantly affected gene was TCFL4, which was 1.42 -fold decreased, $P=0.0003$ ), but did not achieve a magnitude large enough to be listed in Table I. This gene is also known as MAX-like protein (or MLX). We also highlight the increase in expression of transducer of ERBB2, 2 (TOB2, 1.65-fold increased, $P=0.00014$ ) (Table I). The change in TOB2 is noteworthy because this gene is located in close proximity to a schizophrenia susceptibility locus (22q13) and because of the alteration in expression we observed for neuregulin 1, SMDF (sensory and motor neuron derived factor) variant. TOB2 is a transducer of the tyrosine kinase receptors from the ErbB family, which also exert control over NRG signaling. The role of NRG is critical to early development of the central nervous system and includes stimulation of Schwann cell growth as well as generation of acetylcholine receptors at the neuromuscular synapse [reviewed in Falls, 2003]. Of the seven splice variants of NRG on the array, only 
TABLE VII. Location of TDT Peaks Relative to Expression Peaks in Bipolar Disorder

\begin{tabular}{|c|c|c|c|c|c|c|c|}
\hline \multirow[b]{2}{*}{ SNP Ids } & \multicolumn{2}{|c|}{ Haplotype TDT } & \multirow[b]{2}{*}{ dof } & \multirow[b]{2}{*}{ Chr } & \multirow[b]{2}{*}{ Alleles } & \multirow[b]{2}{*}{ MB } & \multirow{2}{*}{$\begin{array}{c}\text { Expression } \\
\mathrm{Z}(\mathrm{MB})\end{array}$} \\
\hline & Chi square & $P$-value & & & & & \\
\hline rs1392096 & 13.42 & 0.0198 & 5 & 1 & $\mathrm{C} / \mathrm{T}$ & 205.3 & $3.31(203)$ \\
\hline rs1166868 & & & & & $\mathrm{C} / \mathrm{T}$ & 205.5 & \\
\hline rs4130547 & & & & & $\mathrm{A} / \mathrm{G}$ & 205.8 & \\
\hline rs1450344 & 10.43 & 0.0153 & 3 & 3 & $\mathrm{~A} / \mathrm{G}$ & 151.5 & $3.30(153)$ \\
\hline rs1388622 & & & & & $\mathrm{A} / \mathrm{G}$ & 152.4 & \\
\hline rs2210798 & 13.29 & 0.0013 & 2 & 6 & $\mathrm{C} / \mathrm{T}$ & 8.5 & $1.93(6)$ \\
\hline rs1591454 & & & & & $\mathrm{C} / \mathrm{G}$ & 8.5 & \\
\hline rs 2225765 & & & & & $\mathrm{~A} / \mathrm{G}$ & 8.5 & \\
\hline rs 2225766 & & & & & $\mathrm{~A} / \mathrm{G}$ & 8.5 & \\
\hline rs2327577 & 13.33 & 0.0098 & 4 & 6 & $\mathrm{G} / \mathrm{T}$ & 135.1 & $2.78(135)$ \\
\hline rs728030 & & & & & $\mathrm{G} / \mathrm{T}$ & 135.2 & \\
\hline rs2327578 & & & & & $\mathrm{C} / \mathrm{T}$ & 135.3 & \\
\hline rs724875 & & & & & $\mathrm{A} / \mathrm{G}$ & 136.7 & \\
\hline rs720565 & & & & & $\mathrm{C} / \mathrm{G}$ & 136.7 & \\
\hline rs721123 & 9.23 & 0.0264 & 3 & 7 & $\mathrm{G} / \mathrm{T}$ & 146.3 & $2.80(136)$ \\
\hline rs721124 & & & & & $\mathrm{C} / \mathrm{T}$ & 146.3 & \\
\hline rs1406288 & & & & & $\mathrm{C} / \mathrm{T}$ & 146.4 & \\
\hline rs719311 & & & & & $\mathrm{A} / \mathrm{T}$ & 147.0 & \\
\hline rs719312 & & & & & $\mathrm{C} / \mathrm{G}$ & 147.0 & \\
\hline rs967306 & 11.33 & 0.0452 & 5 & 9 & $\mathrm{~A} / \mathrm{G}$ & 11.6 & $3.02(2)$ \\
\hline rs958842 & & & & & $\mathrm{G} / \mathrm{T}$ & 11.7 & \\
\hline rs1816823 & & & & & $\mathrm{C} / \mathrm{T}$ & 11.7 & \\
\hline rs2009463 & & & & & $\mathrm{C} / \mathrm{G}$ & 11.7 & \\
\hline rs956094 & & & & & $\mathrm{C} / \mathrm{T}$ & 11.7 & \\
\hline rs317155 & 11.33 & 0.0452 & 5 & 11 & $\mathrm{C} / \mathrm{T}$ & 89.3 & - \\
\hline rs1986670 & & & & & $\mathrm{A} / \mathrm{G}$ & 89.5 & \\
\hline rs1986671 & & & & & $\mathrm{C} / \mathrm{G}$ & 89.5 & \\
\hline rs2167050 & 9.31 & 0.0023 & 1 & 11 & $\mathrm{~A} / \mathrm{C}$ & 132.1 & 3.77 (129) \\
\hline rs921268 & & & & & $\mathrm{A} / \mathrm{G}$ & 132.1 & \\
\hline rs1512981 & 9.04 & 0.0287 & 3 & 12 & $\mathrm{~A} / \mathrm{G}$ & 71.1 & - \\
\hline rs1398562 & & & & & $\mathrm{G} / \mathrm{T}$ & 71.2 & \\
\hline rs2118087 & 9.83 & 0.0200 & 3 & 13 & $\mathrm{~A} / \mathrm{G}$ & 57.5 & - \\
\hline rs719193 & & & & & $\mathrm{G} / \mathrm{T}$ & 57.6 & \\
\hline rs2183493 & & & & & $\mathrm{A} / \mathrm{G}$ & 58.0 & \\
\hline rs2183492 & 9.83 & 0.0200 & 3 & 13 & $\mathrm{C} / \mathrm{T}$ & 58.0 & - \\
\hline rs1330754 & & & & & $\mathrm{C} / \mathrm{T}$ & 58.0 & \\
\hline rs3901894 & 9.03 & 0.0289 & 3 & 13 & $\mathrm{C} / \mathrm{G}$ & 95.2 & - \\
\hline rs544080 & & & & & $\mathrm{A} / \mathrm{C}$ & 95.5 & \\
\hline rs2899589 & 12.00 & 0.0025 & 2 & 15 & $\mathrm{~A} / \mathrm{G}$ & 53.4 & $1.62(46)$ \\
\hline rs725150 & & & & & $\mathrm{C} / \mathrm{T}$ & 53.4 & \\
\hline rs1382859 & 10.81 & 0.0045 & 2 & 15 & $\mathrm{C} / \mathrm{G}$ & 90.4 & $2.16(97)$ \\
\hline rs1382860 & & & & & $\mathrm{A} / \mathrm{G}$ & 90.4 & \\
\hline rs717788 & 12.50 & 0.0285 & 5 & 17 & $\mathrm{C} / \mathrm{T}$ & 11.7 & - \\
\hline rs1519252 & & & & & $\mathrm{A} / \mathrm{G}$ & 12.5 & \\
\hline rs1401539 & & & & & $\mathrm{G} / \mathrm{T}$ & 12.5 & \\
\hline rs952785 & 11.63 & 0.0088 & 3 & 18 & $\mathrm{C} / \mathrm{T}$ & 57.3 & $3.84(53)$ \\
\hline rs582970 & & & & & $\mathrm{C} / \mathrm{T}$ & 57.9 & \\
\hline
\end{tabular}

All expression peaks noted exceeded a $\mathrm{Z}$ score of 1.6 and were within $10 \mathrm{MB}$ of the TDT peak.

the SMDF variant has altered gene expression in schizophrenic subjects versus controls. A full report on these findings was recently reported elsewhere [Petryshen et al., 2004]. Together, our data support further examination of the role of NRG signaling in schizophrenia.

Bipolar disorder. Among the genes with the most consistent and significant changes in expression was one not previously reported in bipolar disorder, termed MAX (1.94-fold increase, $P=0.015$; Table II). The finding regarding increased MAX expression in bipolar disorder is particularly interesting in light of the increased expression of TCFL4/MLX in schizophrenia. The MAX gene encodes for a member of the basic region-helix-loop-helix-zipper proteins [Gilladoga et al., 1992]. The MAX protein has been shown to associate with $\mathrm{N}-$, L-, and c-myc proteins [Gilladoga et al., 1992] and other proteins and transcription factors, such as TCFL4. It has been found that TCFL4 works in conjunction with ChREBP (carbohydrate response element-binding protein) to regulate the expression of genes responsive to glucose [Stoeckman et al., 2004]. Interestingly, we also observed a number of transcripts involved in $\mathrm{G}$ protein signaling to exhibit altered expression in bipolar disorder (e.g., guanine nucleotide binding protein (G protein), beta polypeptide 1; G protein-coupled receptor kinase 5; Table II). Collectively, these data suggest there are prominent changes in cellular transduction mechanisms in this illness.

\section{Functional Gene Group Alterations}

Through the use of custom-written software, we were able to analyze the expression patterns of entire groups of genes that perform the same function in cells. The basis and utility of 
TABLE VIII. Representative Real-Time Quantitative RT-PCR Validation Assays

\begin{tabular}{|c|c|c|c|c|c|c|c|c|}
\hline \multirow[b]{2}{*}{ Disease } & \multirow[b]{2}{*}{ Gene } & \multirow[b]{2}{*}{ Location } & \multicolumn{3}{|c|}{ Array Finding ( $\mathrm{n}=33$ pairs) } & \multicolumn{3}{|c|}{ Real-time ( $\mathrm{n}=19$ pairs) } \\
\hline & & & Fold Chg & $P$-value & \# Probes & Fold Chg & $P$-value & \# Repl \\
\hline $\mathrm{BP}$ & RNA polymerase II, A & $17 \mathrm{p} 13.1$ & -1.09 & 0.497 & 1 & -1.02 & 0.485 & 2 \\
\hline SCZ & Alpha tubulin, ubiquitous & $12 q 13.12$ & 1.04 & 0.640 & 5 & 1.02 & 0.170 & 4 \\
\hline $\mathrm{SCZ}$ & ADAM 19 & $5 q 33.3$ & -1.11 & 0.180 & 2 & -1.28 & 0.026 & 3 \\
\hline SCZ & Serotonin receptor 4 & $5 \mathrm{q} 33.1$ & -1.14 & 0.053 & 3 & -1.31 & 0.018 & 3 \\
\hline $\mathrm{SCZ}$ & Synaptobrevin 2 (VAMP2) & $17 \mathrm{p} 13.1$ & -1.08 & 0.030 & 1 & -1.23 & 0.074 & 3 \\
\hline $\mathrm{SCZ}$ & TCFL4 & $17 \mathrm{q} 21$ & 1.27 & 0.010 & 3 & 1.18 & 0.048 & 2 \\
\hline SCZ & Neuregulin 1, SMDF variant & $8 \mathrm{p} 21-\mathrm{p} 12$ & 1.72 & 0.012 & 1 & 3.80 & 0.014 & 3 \\
\hline
\end{tabular}

Correlation in reported differences $\left(\log _{2}\right.$ scale) for seven transcripts. Array versus PCR: $R=0.951$.

$P$-value superscripts indicate \# tails.

this approach has been reviewed previously [Middleton et al., $2002,2004]$. In the present dataset, we have obtained evidence that several major biological pathways related to lipid and fatty acid metabolism are decreased in bipolar disorder (e.g., sterol transporter, long-chain-fatty-acid-CoA ligase, and cholesterol metabolism; Table VI). In the schizophrenia dataset, these same gene groups were not changed, although the group apolipoprotein A1/A4/E family was similarly decreased (Table VI). Interestingly, among the most increased gene groups in bipolar disorder was the group containing transcripts of the Ezrin family. Ezrin interacts with actin to stabilize uptake process (including the uptake of cholesterol), and has been shown to be important in neurite outgrowth during cortical formation. Ezrin itself is not apparently expressed in neurons, but is abundant within radial glia and migrating cells in the intermediate zone [Johnson et al., 2002]. Together, these data suggest that subjects with schizophrenia and bipolar disorder both exhibit alterations of molecules involved in fatty acid and lipid metabolism that are vital to normal brain function, although the specific genes showing the greatest changes are distinct for each disorder.

\section{Classification by Gene Expression}

We tested the ability of our dataset to correctly distinguish subjects with schizophrenia or bipolar disorder from their unaffected discordant sibs using the nearest neighbor class predictor algorithm (GeneSpring). An iterative approach was used to determine the number of genes and gene neighbors that produced the highest accuracy. The use of 35 potential candidates and 7 nearest neighbors successfully classified 70 of 76 subjects in accordance with their true diagnosis (i.e. unaffected, BP or SCZ).

Of the six misclassified or unclassified subjects, three SCZ patients were classified as BP, one SCZ was misclassified as unaffected, and two subjects were not classified. Thus, in its initial training set, the algorithm had an accuracy of classification of $87 \%$ for schizophrenia ( 27 of 31 correct diagnoses) and $89 \%$ for the combined SCZ and BP subject sets (32 of 36 correct diagnoses). We wish to stress that the small number of BP subjects used in this study likely contributed to a less distinct predictor gene set being obtained for this disease. Interestingly, only one patient was misclassified as an unaffected subject. Moreover, two of the subjects with schizophrenia that were classified as probable bipolar subjects actually had family histories of bipolar disorder and/or carried a Best Estimate Diagnosis of schizoaffective disorder. By convention, schizoaffective disorder, depressed has been considered affected in schizophrenia linkage studies and schizoaffective disorder, bipolar has been considered affected in bipolar linkage studies. This convention may promote confounds that would limit the ability of gene expression profiling. For example, if we eliminate those schizoaffective subjects that were classified as schizophrenics in our linkage studies, three of the four classification errors would be removed. This would increase the diagnostic accuracy to $96 \%$ (27 of 28 correct). Although preliminary, this observation highlights the need for careful evaluation of the nature of schizoaffective disorder and the use of these patients as part of the core phenotype definition. In addition to the nearest neighbor method, we also obtained $100 \%$ accurate classification using a SVM model with our gene expression data. Most of the genes with the highest predictive strength were the same for these two methods, and are listed in Table IV. Notably, several of these predictor genes are located on the loci of interest (e.g., alpha catenin) or have been previously mentioned (e.g., TCFL4).

\section{Cytogenomic Mapping of Expression Data Compared to Linkage/LD Data}

Our method of analyzing the expression of groups of genes in close physical proximity (cytogenomics) has provided clear examples where the abnormalities converge with the loci identified through linkage and/or association screening. Despite the clear limitations of this preliminary study, our results support the potential utility of this multifaceted approach to the study of neuropsychiatric illness. Based on this approach, however, we have already extended these results to specifically test candidate genes within the $5 \mathrm{q}$ linkage region in schizophrenia that displayed abnormal expression patterns and found significant relationships to haplotype-linkage disequilibrium in the same region [Petryshen et al., 2004].

\section{CONCLUSIONS}

Overall, we find that screening of gene expression patterns in PBLs of subjects with schizophrenia or bipolar disorder shows potential both in terms of diagnostic utility as well as revealing new biological insights into these disorders. Much of the data we are accumulating point toward alterations of specific loci and specific biological pathways in each illness. We recognize the need for follow-up studies of our results. Nonetheless, the data we present provide a framework for our ongoing research and allow other groups to test specific hypotheses in their datasets.

\section{ACKNOWLEDGMENTS}

We are very grateful to the families and individuals who participated in these studies. We also thank Xin Zhao for assistance in software development, and Celia Carvalho, Ana Dourado, Isabel Coelho, M.J. Soares, Jose Valente, and Carlos Paz Ferreira for assistance in the clinical ascertainment 
of subjects. Support for this work was derived, in part, from a VA Merit Award (to M.T. Pato) and NIMH grants MH52618 and MH058693 (to C.N. Pato and M.T. Pato).

\section{REFERENCES}

Falls DL. 2003. Neuregulins: Functions, forms, and signaling strategies. Exp Cell Res 284(1):14-30.

Gilladoga AD, Edelhoff S, Blackwood EM, Eisenman RN, Disteche CM. 1992. Mapping of MAX to human chromosome 14 and mouse chromosome 12 by in situ hybridization. Oncogene 7(6):1249-1251.

Irizarry RA, Bolstad BM, Collin F, Cope LM, Hobbs B, Speed TP. 2003. Summaries of Affymetrix GeneChip probe level data. Nucleic Acids Res 31(4):e15

Johnson MW, Miyata H, Vinters HV. 2002. Ezrin and moesin expression within the developing human cerebrum and tuberous sclerosisassociated cortical tubers. Acta Neuropathol (Berl) 104:188-196.

Middleton FA, Mirnics K, Pierri JN, Lewis DA, Levitt P. 2002. Gene expression profiling reveals alterations of specific metabolic pathways in schizophrenia. J Neurosci 22(7):2718-2729.

Middleton FA, Ramos EJ, Xu Y, Diab H, Zhao X, Das UN, Meguid M. 2004a. Application of genomic technologies: DNA microarrays and metabolic profiling of obesity in the hypothalamus and in subcutaneous fat. Nutrition 20:14-25.

Middleton FA, Pato MT, Gentile KL, Morley CP, Zhao X, Eisener AF, et al. 2004b. Genomewide linkage analysis of bipolar disorder by use of a highdensity single-nucleotide-Polymorphism (SNP)genotyping assay: A comparison with microsatellite marker assays and finding of significant linkage to chromosome 6q22. Am J Hum Genet 74:886-897.

Mirnics K, Middleton FA, Marquez AM, Lewis DA, Levitt P. 2000. Molecular characterization of schizophrenia revealed by microarray analysis of gene expression in prefrontal cortex. Neuron 28:53-67.
Pato CN, Pato MT, Kirby A, Petryshen TL, Medeiros H, Carvalho C, Macedo A, Dourado A, Coelho I, Valente J, Soares MJ, Ferreira CP, Lei M, Verner A, Hudson TJ, Morley CP, Kennedy JL, Azevedo MH Daly MJ, Sklar P. 2004. Genome-wide scan in Portuguese Island families implicates multiple loci in bipolar disorder: Fine mapping adds support on chromosomes 6 and 11. Am J Med Genet 127B(1):30-34.

Petryshen TL, Middleton FA, Kirby A, Aldinger KA, Purcell S, Tahl AR, Morley CP, McGann L, Gentile KL, Rockwell GN, Medeiros HM, Carvalho C, Macedo A, Dourado A, Valente J, Ferreira CP, Patterson NJ, Azevedo MH, Daly MJ, Pato CN, Pato MT, Sklar P. 2005. Support for involvement of neuregulin 1 in schizophrenia pathophysiology. Mol Psychiatry 10:328.

Sklar P, Pato MT, Kirby A, Petryshen TL, Medeiros H, Carvalho C, Macedo A, Dourado A, Coelho I, Valente J, Soares MJ, Ferreira CP Lei M, Verner A, Hudson TJ, Morley CP, Kennedy JL, Azevedo MH Lander E, Daly MJ, Pato CN. 2004. Genome-wide scan in Portuguese Island families identifies 5q31-5q35 as a susceptibility locus for schizophrenia and psychosis. Mol Psychiatry 9:213-218.

Stoeckman AK, Ma L, Towle HC. 2004. Mlx is the functional heteromeric partner of the carbohydrate response element-binding protein in glucose regulation of lipogenic enzyme genes. J Biol Chem 279:15662-15669.

Vawter MP, Ferran E, Galke B, Cooper K, Bunney WE, Byerley W. 2004 Microarray screening of lymphocyte gene expression differences in a multiplex schizophrenia pedigree. Schizophr Res 67:41-52.

Wagner AJ, LeBeau MM, Diaz MO, Hay N. 1992. Expression, regulation, and chromosaomal localization of the Max gene. Proc Natl Acad Sci 89(7):3111-3115.

Yeoh EJ, Ross ME, Shurtleff SA, Williams WK, Patel D, Mahfouz R, Behm FG, Raimondi SC, Relling MV, Patel A, Cheng C, Campana D, Wilkins D, Zhou X, Li J, Liu H, Pui CH, Evans WE, Naeve C, Wong L, Downing JR. 2002. Classification, subtype discovery, and prediction of outcome in pediatric acute lymphoblastic leukemia by gene expression profiling. Cancer Cell 1:133-143. 